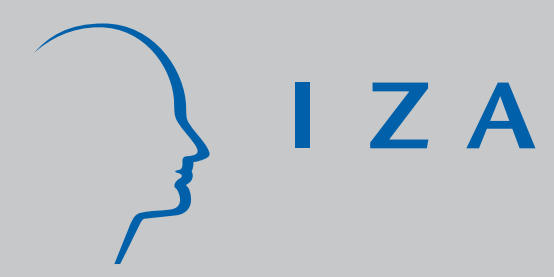

IZA DP No. 1777

How Many Winners Are Good to Have?

On Tournaments with Sabotage

Christine Harbring

Bernd Irlenbusch

September 2005 


\title{
How Many Winners Are Good to Have? On Tournaments with Sabotage
}

\author{
Christine Harbring \\ University of Cologne \\ Bernd Irlenbusch \\ London School of Economics \\ and IZA Bonn
}

Discussion Paper No. 1777

September 2005

\author{
IZA \\ P.O. Box 7240 \\ 53072 Bonn \\ Germany \\ Phone: +49-228-3894-0 \\ Fax: +49-228-3894-180 \\ Email: iza@iza.org
}

\begin{abstract}
Any opinions expressed here are those of the author(s) and not those of the institute. Research disseminated by IZA may include views on policy, but the institute itself takes no institutional policy positions.

The Institute for the Study of Labor (IZA) in Bonn is a local and virtual international research center and a place of communication between science, politics and business. IZA is an independent nonprofit company supported by Deutsche Post World Net. The center is associated with the University of Bonn and offers a stimulating research environment through its research networks, research support, and visitors and doctoral programs. IZA engages in (i) original and internationally competitive research in all fields of labor economics, (ii) development of policy concepts, and (iii) dissemination of research
\end{abstract} results and concepts to the interested public.

IZA Discussion Papers often represent preliminary work and are circulated to encourage discussion. Citation of such a paper should account for its provisional character. A revised version may be available directly from the author. 


\section{ABSTRACT}

\section{How Many Winners Are Good to Have? On Tournaments with Sabotage*}

From an employer's perspective a tournament should induce agents to exert productive activities but refrain from destructive ones. We experimentally test the predictive power of a tournament model which suggests that - within a reasonable framework - productive and destructive activities are not influenced neither by the number of agents taking part in the tournament nor by the fraction of the winner prizes. Our results clearly confirm that sabotage in tournaments indeed occurs. While tournament size has virtually no effect on behavior, a balanced fraction of winner and loser prizes seems to particularly enhance productive activities.

JEL Classification: D23, J33, L23, C72

Keywords: relative performance evaluation, personnel economics, sabotage, experiments

Corresponding author:

Bernd Irlenbusch

London School of Economics

Houghton Street

London, WC2A 2AE

United Kingdom

Email: b.irlenbusch@Ise.ac.uk

\footnotetext{
* We thank two anonymous referees, Christian Grund, Matthias Kräkel, Reinhard Selten, and Dirk Sliwka for valuable comments. All errors are our own. We are grateful to Sebastian Kube who programmed the experimental software. Financial support by the Deutsche Forschungsgemeinschaft through grant KR2077/2-1, KR2077/2-3, IR43/1-1 and HA 4462/1-1 is gratefully acknowledged.
} 


\section{Introduction}

Incentive schemes that are based on a relative evaluation of agents are analyzed by economists within the framework of tournament theory (for an overview see e.g., GIBBONS 1998, Lazear 1999, Prendergast 1999). While many advantages are credited to such reward mechanisms, e.g., mitigation of hidden action and hidden information problems (see e.g., Malcolmson 1984, 1986), also severe drawbacks have been identified. The most prominent are collusion and sabotage between agents. While economists usually agree that cooperation between members of an organization is desirable for the institution as a whole, in tournaments cooperation among agents is called "collusion" and regarded as a major danger of pay based on relative performance. Furthermore, if agents do not cooperate but intensely compete against each other, sabotage between agents may arise. Although competition is the intended driving force of tournaments, competition at the expense of the employer in the form of destructive activities is, of course, highly undesirable. The problem of sabotage results from the fact that agents can choose between at least two dimensions of activities in order to improve their relative position, i.e., they cannot only intensify their productive effort but also deteriorate their competitors' performance by means of destructive activities. ${ }^{1}$ Since there are several degrees of freedom regarding the implementation of relative reward schemes from the employer's point of view the important question arises whether and how different tournament designs may affect the level of productive and destructive activities among employees.

In recent times, interest in the potential advantages and drawbacks of competitive incentive schemes within organizations have dramatically increased in the course of the controversial debate on forced rankings. ${ }^{2}$ If employees are rated according to a forced ranking they compete for a good evaluation as the absolute number of good ratings is fixed ex ante via a forced distribution of performance evaluations. The relative performance evaluation is often directly linked to a bonus pay system, the decision on promotion of high performers, or advising low performers to leave the company. Particularly the latter management practice has been heavily criticized as it is feared that cooperation between employees within an

\footnotetext{
${ }^{1}$ In reality, sabotage is pervasive whenever relative performance pay is encountered. For a prominent example from sports recall the Tonya Harding-Nancy Kerrigan case where Harding's rival Kerrigan was injured in an attack hatched by Harding’s ex-husband to keep Kerrigan off the Olympic ice skating team in 1994.

2 Forced rankings are usually implemented to force evaluating managers to sufficiently differentiate their ratings, i.e., to use the whole range of grades (see, e.g., MurpHy 1992). According to estimates, a quarter of the Fortune 500 companies (e.g., General Electric, Cisco, Intel, Hewlett Packard, etc.) link part of individual benefits to a relative performance evaluation (see BOYLE 2001). Recently, a statement made by Infineon's former CEO, Schumacher, was extensively discussed in Germany: Schumacher announced that the $5 \%$ of low performers within Infineon had to leave the company. This is why forced rankings are also known as "rank and yank". For a critical discussion on forced ranking systems see e.g., PFEFFER and SUTTON (1999).
} 
organization is put at risk - or even worse - that agents exert destructive activities. Another pervasive example for a tournament among individuals whose cooperation seems essential for the company's business performance is the competition for top leadership jobs. In organizations a sabotage activity can take any form of blocking the cooperation such as actively withholding viable information, passing on false information, or damaging work tools used by others.

In this study we experimentally test the predictive power of an economic model which suggests that - within certain tournament design limits - productive and destructive activities are not influenced neither by the size of the tournament nor by the fraction of the winner prizes. We find that, although it severely harms the employer, sabotage nevertheless happens where the opportunity for this activity exists. Furthermore, as predicted by the model, the level of effort and sabotage is not affected by the size of the tournament. However, contrary to the predictions, activity levels are influenced by the share of winners. In fact, the tournament structure which elicits the highest levels of productivity also tends to lead to higher-than predicted levels of sabotage. We vary two parameters of tournament design: the number of agents and the number of winner prizes. We analyze repeated tournaments with two, four as well as eight agents. The tournament model we aim to investigate is close to the classical model of LAZEAR (1989).

It appears to be quite plausible that to a certain degree an employer in an organization is able to deliberately decide on different design issues when setting up a tournament. For instance she can choose how many agents participate in the tournament and how large the fraction of winner prizes should be. As an example consider an incentive system for employees implemented as a bonus scheme. In such a case, tournament prizes may serve as efforteliciting incentive tools that grant agents a payoff in addition to their base salary. However, in organizations also "naturally" given tournaments occur in the form of promotion tournaments. The promotion to a higher hierarchical rank that is often associated with a higher wage level constitutes the winner prize in such tournaments. It is obvious that the employer may determine the amount of the pay increase, i.e., the prize spread of the tournament, in case of a promotion tournament. At first sight, however, it is not so obvious whether the employer may also determine the number of participants and winner prizes in a promotion tournament. However, she may decide on the number of employees competing for a certain promotion in the long run by assigning employees to one career path. Moreover, as she may decide how many vacancies are to be filled by promoting employees within the internal labor market and 
how many jobs are to be filled by external recruitments (see e.g. GRUND 2005) the fraction of winner prizes could well be within the employer's range of decision.

The question of how human actors react to different incentive schemes when interacting with each other is at its very heart an empirical one. If one wishes to analyze destructive activities in organizations, however, severe data problems arise because sabotage in general is strictly forbidden and thus, it is performed in secret. Furthermore, field data cannot easily be used to compare different design issues because it is hard to find real-world tournaments that vary only with regard to the characteristics under consideration. ${ }^{3}$ To overcome these problems we opt for an experimental approach. Controlled experiments have the decisive advantage that all strategic options adopted by agents can be observed in clearly defined interactive situations. Furthermore, the influence of clear-cut institutional modifications on behavior can be analyzed. For a comprehensive discussion of advantages and disadvantages of the experimental method used to analyze labor economic issues see FALK and FEHR (2003). Our experimental setup resembles previous studies on tournaments (e.g. BULL, SCHOTTER, and Weigelt 1987, Weigelt, Dukerich, and Schotter 1989, Schotter and Weigelt 1992, NALbantian and Schotter 1997, VAn DiJk, Sonnemans, Winden 2001, OrRison, Schotter, and Weigelt 2004). OrRison, Schotter, and Weigelt (2004) also vary the tournament size and the fraction of winner prizes. However, they as well as all other studies mentioned above do not consider the possibility to exert destructive activities. For experimental studies on sabotage in tournaments see HARBRING and IRLENBUSCH (2003 b, 2004, 2005). The study HARBRING and IRLENBUSCH (2004) is closest to the present one as variations of the prize spread and the fraction of winner prizes are investigated while keeping the tournament size constant. In the two studies HARBRING and IRLENBUSCH (2003 b, 2005) interactions between a principal and agents are analyzed. While the principal may repeatedly commit herself to certain design features of the tournament agents may respond to their choices by exerting effort and sabotage.

We employ a simple tournament model with two activity dimensions. The principal is not allowed to endogenously select any parameters of tournament design as we intend to analyze the pure incentive effects of a tournament without a repeated interaction of a principal and

\footnotetext{
3 There are many interesting studies using data from sports, e.g., EHRENBERG and BogNANNO (1990) on golf tournaments or BECKER and HUSELID (1992) on car-racing, or company data., e.g., MAIN, O'REILLY, and WADE (1993) and ERIKSSON (1999). There are two studies that approach the analysis of sabotage in real-world settings. GARICANO and PALACIOS-HUERTA (2000) analyze the effect of an increase in the prize spread on the behavior of soccer players from the Spanish soccer league. They approximate the intensity of sabotage by measuring the number of defenders and yellow/red cards. DRAGO and GARVEY (1998) analyze the effect of pay dispersion on helping effort in Australian companies. For an overview see HARBRING and IRLENBUSCH (2003a).
} 
agents. ${ }^{4}$ Each agent's output is dependent on his own effort, other agents' sabotage activities, and a random component. The agents' decisions influence the payoff of a principal who is assigned to each group of agents. There are two intuitive possibilities to model sabotage activities. Either exerting sabotage harms a single other player or more players are affected by a sabotage activity. HARBring, IRLENBUSCH, KRÄKEL and SELTEN (2004) provide an experimental study on sabotaging individuals in contests with homogeneous and heterogeneous contestants. For a theoretic approach see CHEN (2003). In this study, we model a sabotage activity that reduces the output of all other competitors in the tournament. According to our framework effort and sabotage activities of agents are independent of the tournament size and the fraction of winner prizes in the symmetric equilibrium. It is, however, important to note that the sabotage problem aggravates if the number of participants in the tournament is increased as exerting sabotage reduces the output of all participants in the tournament. Thus, the severity of the sabotage problem is a result of the tournament size. To investigate a serious sabotage problem we also analyze tournaments with many participants in which in equilibrium destructive activities overcompensate productive effort.

The remainder of the paper is organized as follows: In section 2 the model with agents' activities from two dimensions is presented, and the game theoretic solution is derived. Section 3 describes the experimental design and procedure. Section 4 summarizes our experimental results which are discussed in section 5. Section 6 concludes.

\section{A Simple Model of Tournaments with Two Activity Dimensions}

In this section, we introduce a simple model of rank-order tournaments in which agents can choose activities from two dimensions: Productive effort and sabotage. While from an agent's perspective the two activities are substitutes in the sense that both improve an agent's relative output position, they differ in the consequences for the principal, i.e., total output is increased by effort and decreased by sabotage. We consider a game of $n+1$ players, i.e. $n$ agents and one principal. Agents take part in a tournament in which they compete for $n \lambda$ winner prizes $(0<\lambda<1)$, i.e., agents with the $(1-\lambda) n$th lowest output or less receive loser prizes. We denote the winner prize by $M$, the loser prize by $m$ with $(M>m \geq 0)$ and the prize spread

\footnotetext{
4 Several other studies deal with the interaction of a principal and agents by investigating how subjects' behavior is influenced by different contract designs (GüTH, KLOSE, KÖNIGSTEIN, and SchwALBACH 1998, Cabrales and Charness 2000, Fehr, Klein, and Schmidt 2001, Güth, Königstein, Kovacs, and ZalaMezo 2001, ANDERHub, GÄChTER, and KÖnigstein 2002, IRLENBUSCH and SliwKA 2005). They, however, do not analyze the interaction of a principal and agents in the context of rank-order tournaments.
} 
$(M-m)$ by $\Delta$. A strategy of agent $i$ is a pair $\left(e_{i}, s_{i}\right)$ where $e_{i} \in[0, \ldots, \bar{e}]$ denotes an effort level and $s_{i} \in[0, \ldots, \bar{s}]$ is a sabotage activity. The latter negatively influences the output of all other agents, i.e., the output $y_{i}$ of agent $i$ is determined by the following production function

$$
y_{i}=e_{i}+\varepsilon_{i}-\sum_{i \neq j} s_{i}
$$

with $\varepsilon_{i}$ as a random variable which is uniformly distributed over the interval $[-\bar{\varepsilon},+\bar{\varepsilon}]$ and assumed to be i.i.d. for all agents. The random component, $\varepsilon_{i}$, can be thought of as production luck or measurement error. The composition of the output $y_{i}$ shows that each unit of sabotage reduces the output of other agents by one unit. Every agent who exerts effort or performs a sabotage activity has to bear costs, which are described by the two convex functions $C_{e}\left(e_{i}\right)$ and $C_{s}\left(s_{i}\right)$. It is assumed that all agents face the same cost functions for productive effort and the sabotage activity and that this is common knowledge. ${ }^{5}$ All agents simultaneously submit their decisions regarding both activities. The expected payoff for agent $i$ is given by

$$
E \Pi_{i}\left(e_{i}, e_{-i}, s_{i}, s_{-i}\right)=F\left(e_{i}, e_{-i}, s_{i}, s_{-i}\right) M+\left[1-F\left(e_{i}, e_{-i}, s_{i}, s_{-i}\right)\right] m-C_{e}\left(e_{i}\right)-C_{s}\left(s_{i}\right)
$$

with $F\left(e_{i}, e_{-i}, s_{i}, s_{-i}\right)$ denoting the probability for agent $i$ to receive a winner prize if all other agents choose effort levels $e_{-i}=\left(e_{1}, e_{2}, \ldots, e_{i-1}, e_{i+1}, \ldots, e_{n}\right)$ and sabotage activities $S_{-i}=\left(s_{1}, S_{2}, \ldots, S_{i-1}, S_{i+1}, \ldots, S_{n}\right)$.

The principal is remunerated in proportion to the sum of outputs generated by agents:

$$
E \Pi_{P}(e, s)=\tau\left[E\left(\sum_{i} y_{i}\right)+n \kappa\right]=\tau\left[\sum_{i} e_{i}-\sum_{i} \sum_{j \neq i} s_{j}+n \kappa\right]
$$

where $\tau$ indicates the value of one unit of output for the principal and $\kappa$ denotes the minimal output each agent is expected to produce if the agents simply show a work-to-rule behavior.

\footnotetext{
${ }^{5}$ It seems realistic to assume that agents in an organization who are in close contact to each other can observe their cost of effort functions, i.e., the type of players they are competing with. Tournaments with heterogeneous agents who differ in their cost functions representing different abilities of agents are, for example, analyzed in LAZEAR and ROSEN (1981), O’KEEFFE, VisCusi and ZECKHAUSER (1984) and MCLAUGHLIN (1988). Ceteris paribus agents who have higher effort cost, exert lower effort in equilibrium than those with lower costs for the same effort level. Experimental studies on asymmetric tournaments are provided by WEIGELT, DUKERICH and SCHOtTer (1989), SchotTer and Weigelt (1992), HARBring and Ruchala (2005) and HARBring, IRLENBUSCH, KRÄKEL and SELTEN (2004). Experimental findings indicate that agents who are disadvantaged by higher costs of effort exert more effort than theoretically predicted.
} 
Our tournament incentives are supposed to induce output exceeding this baseline output. By multiplying the minimal output with the number of participants we take into account that in general larger groups have a higher productivity. Thus, the principal's payoff increases with the productive activities of agents $e=\left(e_{1}, e_{2}, \ldots, e_{n}\right)$ and reduces with the sabotage activities $S=\left(s_{1}, S_{2}, \ldots, s_{n}\right)$. The principal may not take any action. By including the (passive) principal into our model the different nature of the two activity dimensions - effort and sabotage becomes apparent. While both activities have the same strategic effect from an agent's perspective the productive effort increases the principal's payoff and the sabotage activity decreases it. As the principal is not allowed to endogenously decide on the compensation scheme we simplify our setting by abstracting from the constant wage costs for a given tournament design when we determine the principal's payoff. Note that in reality this might not necessarily be the case since a manager's bonus often depends on the costs incurred by his decisions. Thus, if the principal has the opportunity to actively select one of the wage design features his payoff should also depend on the costs (such a setting is modeled for example in HARBRING and IRLENBUSCH 2003 b, 2005).

As a benchmark let us have a look at the equilibrium behavior. For simplicity, we concentrate on cost functions of the type $C_{e}\left(e_{i}\right)=e_{i}{ }^{2} / c_{e}$ and $C_{s}\left(s_{i}\right)=s_{i}{ }^{2} / c_{s}$. For our analysis we assume that all agents are risk neutral, purely money maximizing and that there exists an interior symmetric equilibrium in pure strategies. With $e^{*}$ and $s^{*}$ as equilibrium activities that are exerted by other agents the expected payoff of an agent $i$ can be rewritten as

$$
E \Pi_{i}\left(e_{i}, e_{-i}, s_{i}, s_{-i}\right)=m+F\left(e_{i}, e_{-i}, s_{i}, s_{-i}\right) \Delta-e_{i}^{2} / c_{e}-s_{i}^{2} / c_{s}
$$

We derive the first order conditions

$$
\frac{\partial F\left(e_{i}, e_{-i}, s_{i}, s_{-i}\right)}{\partial e_{i}} \Delta=\frac{2 e_{i}}{c_{e}} \text { and } \frac{\partial F\left(e_{i}, e_{-i}, s_{i}, s_{-i}\right)}{\partial s_{i}} \Delta=\frac{2 s_{i}}{c_{s}}
$$

Given our assumptions on the distribution of the random components in the production function one can show that in a symmetric equilibrium the marginal probabilities of winning are constant and depend only on the size of the interval from which the random component is drawn (see Appendix) ${ }^{6}$, i.e., one can show that

\footnotetext{
${ }^{6}$ We only consider symmetric equilibria in pure strategies assuming their existence. As we model homogenous agents the examination of symmetric equilibria seems plausible. Of course, we are aware that also asymmetric equilibria may exist. The marginal probability of winning is derived in the Appendix. Proofs for the cases $\lambda=$ $1 / n$ and $\lambda=(n-1) / n$ are given by KRÄKEL (2000). See also ORRISON, SCHOTTER, and WEIGELT (2004).
} 


$$
\frac{\partial F\left(e_{i}, e_{-i}, s_{i}, s_{-i}\right)}{\partial e_{i}}=\frac{\partial F\left(e_{i}, e_{-i}, s_{i}, s_{-i}\right)}{\partial s_{i}}=\frac{1}{2 \bar{\varepsilon}} .
$$

Thus, our first order conditions reduce to

$$
\frac{1}{2 \bar{\varepsilon}} \Delta=\frac{2 e_{i}}{c_{e}} \wedge \frac{1}{2 \bar{\varepsilon}} \Delta=\frac{2 s_{i}}{c_{s}}
$$

from which we obtain the effort level and the sabotage activity played in equilibrium

$$
e^{*}=\frac{\Delta c_{e}}{4 \bar{\varepsilon}} \text { and } s^{*}=\frac{\Delta c_{s}}{4 \bar{\varepsilon}}
$$

To ensure that an interior solution exists and that agents have no incentive to deviate to activities of zero the following condition is assumed to be satisfied:

$$
\lambda \Delta \geq C_{e}\left(e^{*}\right)+C_{s}\left(s^{*}\right)
$$

This guarantees that the expected gain of an agent is not lower than his cost. Thus, in the experimental settings parameters have to be chosen such that this condition is fulfilled. Moreover, the highest possible eligible effort level must exceed the equilibrium effort level, i.e., $e^{*}<\bar{e}$, and this has to hold analogously for the sabotage activity $\left(s^{*}<\bar{s}\right)$.

Note that an increase in the prize spread leads to higher effort as well as sabotage activities and that the marginal cost of effort and sabotage are equal in equilibrium. Especially interesting is the finding that - given the existence of the symmetric equilibria in pure strategies for which in particular it is necessary that the number of participants $n$ is small enough and the winner prize $M$ is large enough; see condition (9) - the equilibrium activity levels do neither depend on the tournament size $n$ nor do they change with the fraction of winner prizes $\lambda$. Essentially, this is due to the fact that for deriving the symmetric equilibrium only the marginal probability of winning is decisive. In the symmetric equilibrium, all agents choose the same effort level and the same sabotage activity. Thus, the ranking of output is determined by the realization of the random component $\varepsilon_{i}$. Under the assumption of $\varepsilon_{i}$ being uniformly distributed the marginal probability of winning is constant for different fractions of winner prizes and different tournament sizes. To sketch the intuition of this result imagine that only the agent who is at the "marginal position" of the ranking between receiving the loser and winner prize can improve his outcome, i.e., only the agent with the highest output of all 
agents receiving the loser prize could obtain a winner prize instead of a loser prize via marginally increasing his effort. The location of this "marginal position" changes with the fraction of winner prizes but the marginal probability of winning remains constant for all “marginal positions”. As a consequence, the marginal probability of winning is constant for each fraction of winner prizes.

\section{Experimental Design and Procedure}

In our treatments, tournament size $n$ and the fraction of winner prizes $\lambda$ are varied. Either two, four or eight subjects may participate in tournaments with different fractions of winner prizes which may amount to $\lambda \in\{1 / 4,1 / 2,3 / 4\}$ (see Table 1 ).

Table 1: Treatments resulting from the variation of tournament size $n$ and fraction of winner prizes $\lambda$

\begin{tabular}{cccc}
\hline \hline & $\lambda=1 / 4$ & $\lambda=1 / 2$ & $\lambda=3 / 4$ \\
\cline { 2 - 4 }$n=2$ & & $1 \mathrm{~m} 1 \mathrm{M}$ & \\
$n=4$ & $3 \mathrm{~m} 1 \mathrm{M}$ & $2 \mathrm{~m} 2 \mathrm{M}$ & $1 \mathrm{~m} 3 \mathrm{M}$ \\
$n=8$ & $6 \mathrm{~m} 2 \mathrm{M}$ & $4 \mathrm{~m} 4 \mathrm{M}$ & $2 \mathrm{~m} 6 \mathrm{M}$ \\
\hline \hline
\end{tabular}

The naming of the treatments follows the scheme „xmyM“, where $x$ denotes the number of loser and $y$ the number of winner prizes.

The loser prize and the prize spread are constant in all treatments. Both are set to 100 Talers. Other parameters are chosen as follows: the size of the interval the random component is drawn from is $\bar{\varepsilon}=60$, the parameters for the cost functions are $c_{e}=76.8$ and $c_{s}=19.2$, the maximal feasible productive activity is $\bar{e}=100$ and the maximal destructive activity is $\bar{s}=50$. We assume the exertion of sabotage to be more expensive than productive effort (with $C_{e}>C_{s}$ ) as agents who exert a destructive activity have to exert additional effort to conceal their sabotage activity. According to the game theoretic prediction derived above agents choose a productive effort level of $e^{*}=32$ and a sabotage activity of $s^{*}=8$ in all treatments. It is important to note that the output generated in equilibrium is negative in our large tournaments with eight participants. Table 2 provides an overview over the design of our seven treatments. 
Table 2: Design of the experiment

Treatments

\section{Parameters}

fraction of winner prizes $\lambda$

tournament size

prize differential $\Delta$

productive effort in equilibrium $e^{*}$

sabotage activity in equilibrium $s^{*}$

equilibrium output $y^{*}$ per agent

$1 \mathrm{~m}$

\section{Design}

\# agents

\# principals

\# observations

\begin{tabular}{c|ccc|ccc}
$1 / 2$ & $1 / 4$ & $1 / 2$ & $3 / 4$ & $1 / 4$ & $1 / 2$ & $3 / 4$ \\
2 & 4 & 4 & 4 & 8 & 8 & 8 \\
100 & 100 & 100 & 100 & 100 & 100 & 100 \\
32 & 32 & 32 & 32 & 32 & 32 & 32 \\
8 & 8 & 8 & 8 & 8 & 8 & 8 \\
24 & 8 & 8 & 8 & -24 & -24 & -24 \\
& & & & & & \\
24 & 32 & 32 & 32 & 64 & 64 & 64 \\
12 & 8 & 8 & 8 & 8 & 8 & 8 \\
12 & 8 & 8 & 8 & 8 & 8 & 8 \\
\hline
\end{tabular}

The experiment was conducted in the Laboratory of Experimental Research at the University of Bonn. The sessions were computerized using the toolbox RatImage, ABBINK and SADRIEH (1995). In total 372 subjects - predominantly students of economics or law - participated, each in one session only. A session lasted for about 1-1.5 hours and consisted of 18 or 20 participants. Before starting the experiment instructions were read aloud to the participants. ${ }^{7}$ To keep potential suggestive influences as small as possible a neutral language was used. Expressions like “effort”, “tournament”, “prize” or "sabotage” were not mentioned. Participants received two cost tables, from which they could learn the costs of all feasible numbers A (productive activities) and the costs of all feasible numbers B (destructive activities). Participants were randomly and anonymously matched to groups of three, five or nine. In each group one participant was randomly selected to be the player of type I (principal), and the other players were of type II (agents). The matching of groups and the assignment of the types of players were kept constant during the whole experiment. Each of the groups in one session simultaneously participated in 20 rounds each implementing the same tournament. At the beginning participants were only informed about the tournament design employed in their session without indication of the other designs.

\footnotetext{
${ }^{7}$ An example of the instructions can be found in the Appendix. Original instructions were in German and can be obtained from authors upon request.
} 
The principals of one session were seated into a separate room. After each round they were informed about their agents' individual outputs and received the task to calculate their own payoffs. Thereby principals were kept busy during the experiment. Moreover, it was intended to let the agents know that the principals had to fulfill a tedious task so that the agents had no obvious reason for envying the principal and therefore for preventing them from earning money. During the instructions participants were informed about the payoff function of the player of type I (principal) and that type I players would have to calculate their own payoffs. As the principals did not take any decision they were allowed to talk to each other but not to the agents. The agents of each session were seated in separate cubicles in the laboratory. They were not allowed to communicate with each other. In each round each agent had to choose a

number A and a number B. For the convenience of participants the experimental software calculated the costs of the numbers chosen as well as the sum of costs incurred for both numbers immediately after inserting the decisions. Participants could still modify numbers even after the costs were depicted on the screen. After the participants had ultimately chosen their final numbers the outputs were calculated, and agents learned whether they had received the winner or loser prize. They were neither informed about the realization of their random component nor about their output nor about the numbers that the other participants in their group had chosen. Agents were shown the payoff of their principal after each round. During the experiment costs and payoffs were given in the fictitious currency Taler which were exchanged at a rate - known to the participants - of 0.51 Euro per 100 Talers after the experiment. Payment was anonymous. The participants' average payoff was 12.26 Euro. After the experiment participants were asked to fill in a questionnaire.

\section{Experimental Results}

In this section we present our experimental results. The effect of the variation of one of the two parameters - tournament size and fraction of winner prizes - is analyzed while keeping the other parameter constant. Additionally, we analyze the development of behavior over rounds.

\subsection{Tournament Size}

According to our game theoretic prediction the number of agents in a tournament should not influence behavior. Indeed, we do not find a difference at a conventional level of significance between the treatments of different sizes regarding productive and destructive activities in 
tournaments with the same fraction of winner prizes. For an overview of aggregated results of all treatments see Table 3.

Table 3: Overview of experimental results regarding average activity levels

\begin{tabular}{|c|c|c|c|c|c|c|c|}
\hline \multirow{4}{*}{$\begin{array}{l}\text { tournament size } n \\
\text { fraction of winner prizes } \lambda\end{array}$} & \multicolumn{7}{|c|}{ treatments } \\
\hline & $1 \mathrm{~m} 1 \mathrm{M}$ & $3 \mathrm{~m} 1 \mathrm{M}$ & $2 \mathrm{~m} 2 \mathrm{M}$ & $1 \mathrm{~m} 3 \mathrm{M}$ & $6 \mathrm{~m} 2 \mathrm{M}$ & $4 \mathrm{~m} 4 \mathrm{M}$ & $2 \mathrm{~m} 6 \mathrm{M}$ \\
\hline & 2 agents & & 4 agents & & & 8 agents & \\
\hline & $1 / 2$ & $1 / 4$ & $1 / 2$ & $3 / 4$ & $1 / 4$ & $1 / 2$ & $3 / 4$ \\
\hline average effort & $\begin{array}{l}42.85^{++} \\
(14.90)\end{array}$ & $\begin{array}{c}32.24 \\
(17.44)\end{array}$ & $\begin{array}{c}43.99^{+++} \\
(14.93)\end{array}$ & $\begin{array}{l}38.32^{++} \\
(11.27)\end{array}$ & $\begin{array}{c}30.90 \\
(16.15)\end{array}$ & $\begin{array}{c}41.79^{+++} \\
(16.24)\end{array}$ & $\begin{array}{l}37.18 \\
(7.41)\end{array}$ \\
\hline effort in equilibrium & 32 & 32 & 32 & 32 & 32 & 32 & 32 \\
\hline average sabotage & $\begin{array}{c}14.63^{+++} \\
(6.72)\end{array}$ & $\begin{array}{l}12.52 \\
(7.72)\end{array}$ & $\begin{array}{c}11.60^{+++} \\
(6.22)\end{array}$ & $\begin{array}{l}11.96 \\
(4.59)\end{array}$ & $\begin{array}{c}10.36^{++} \\
(7.60)\end{array}$ & $\begin{array}{c}13.88^{+++} \\
(6.35)\end{array}$ & $\begin{array}{c}12.00^{+++} \\
(4.81)\end{array}$ \\
\hline sabotage in equilibrium & 8 & 8 & 8 & 8 & 8 & 8 & 8 \\
\hline output per agent & 28.23 & $-5.32^{--}$ & 9.18 & 2.45 & $-41.61^{--}$ & $-55.35^{--}$ & $-46.84^{---}$ \\
\hline $\begin{array}{l}\text { output per agent in } \\
\text { equilibrium }\end{array}$ & 24 & 8 & 8 & 8 & -24 & -24 & -24 \\
\hline
\end{tabular}

Standard deviations of average effort and sabotage over rounds are given in parentheses.

By using the Wilcoxon Signed Rank Test (two-tailed) we state the level of significance at which the null hypothesis can be rejected in favor of the alternative hypothesis that average values are above (+) or below (-) the equilibrium level:

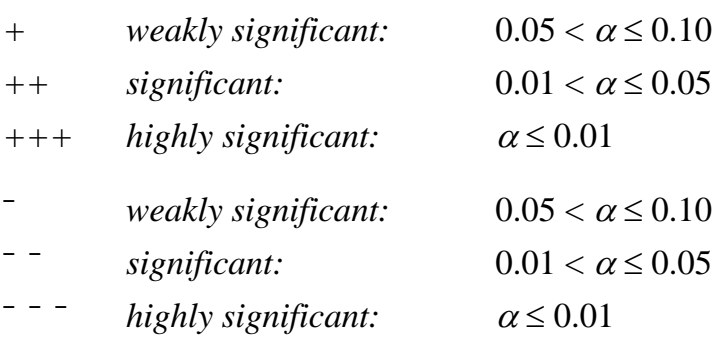

One might assume that collusion is observed, especially in very small tournaments with only two participants. We do, however, not find any hints indicating collusive activities. This might be due to the influence of the random component which complicates coordination. According to the theoretical analysis presented above tournaments of different sizes should result in different levels of output produced by agents even though the exertion of effort and sabotage activities does not depend on the number of participants. This is due to our modeling of the sabotage activity, i.e., sabotaging affects all other agents in the tournament. Thus, the cumulated detrimental effect of a certain level of sabotage in large tournaments exceeds the effect in small tournaments in terms of total individual output units destroyed. We can 
confirm theory regarding these qualitative differences between differently-sized tournaments. The average output is significantly highest in tournaments with two agents and lowest in large tournament with eight agents ( $1 \mathrm{~m} 1 \mathrm{M}$ vs. $2 \mathrm{~m} 2 \mathrm{M}: \alpha=0.000$, 3m1M vs. $6 \mathrm{~m} 2 \mathrm{M}: \alpha=0.001,2 \mathrm{~m} 2 \mathrm{M}$ vs. 4m4M: $\alpha=0.000,1 \mathrm{~m} 3 \mathrm{M}$ vs. $2 \mathrm{~m} 6 \mathrm{M}: \alpha=0.000$, Mann-Whitney $\mathrm{U}$ test, two-tailed).

In large tournaments with eight agents the average output per group is significantly more often below the equilibrium prediction in each treatment than above. This is mainly due to the sabotage activities which quite often lie above the equilibrium prediction. Thus, the detrimental effect of the sabotage activities aggravates with an increasing tournament size.

\subsection{Fraction of Winner Prizes}

\section{i) Effort}

In the treatments with four and eight participants the influence on behavior of different fractions of winner prizes can be analyzed. Table 3 as well as Figures 1 and 2 already indicate an interesting effect: Average effort seems to be highest for treatments with a balanced fraction of winner and loser prizes, i.e., with $\lambda=1 / 2$. Note, that the fraction of winner prizes should be irrelevant for the agents' behavior according to our game theoretic analysis.
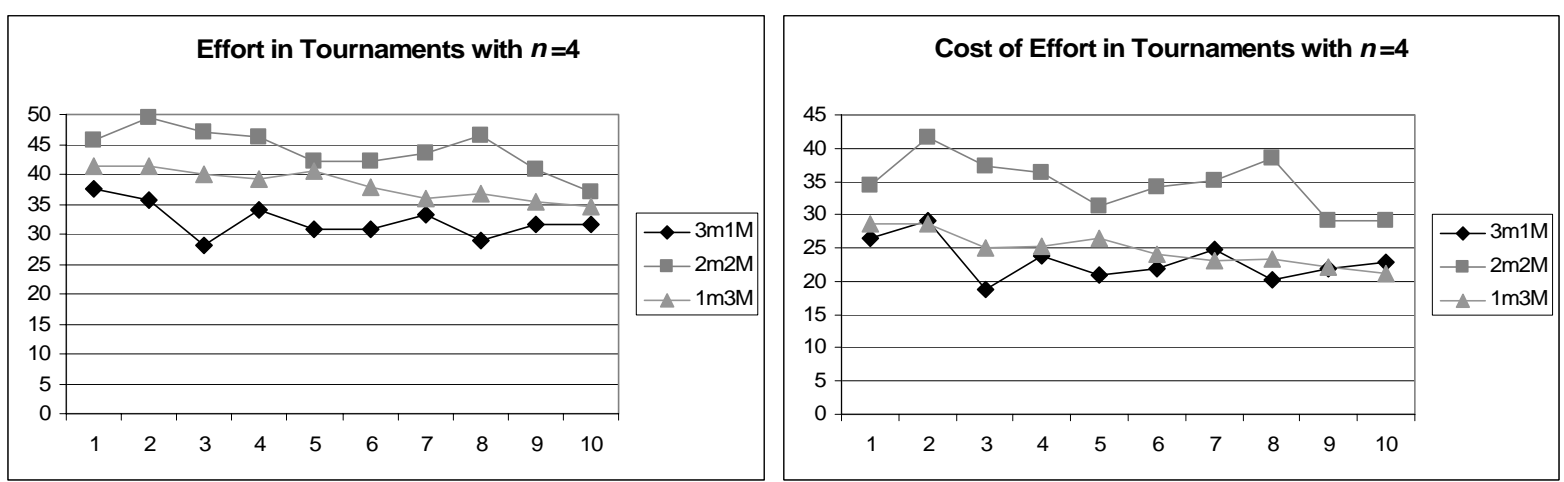

Figure 1: Average efforts and resulting costs over rounds in four-person tournaments. The figure shows averages over two consecutive rounds.
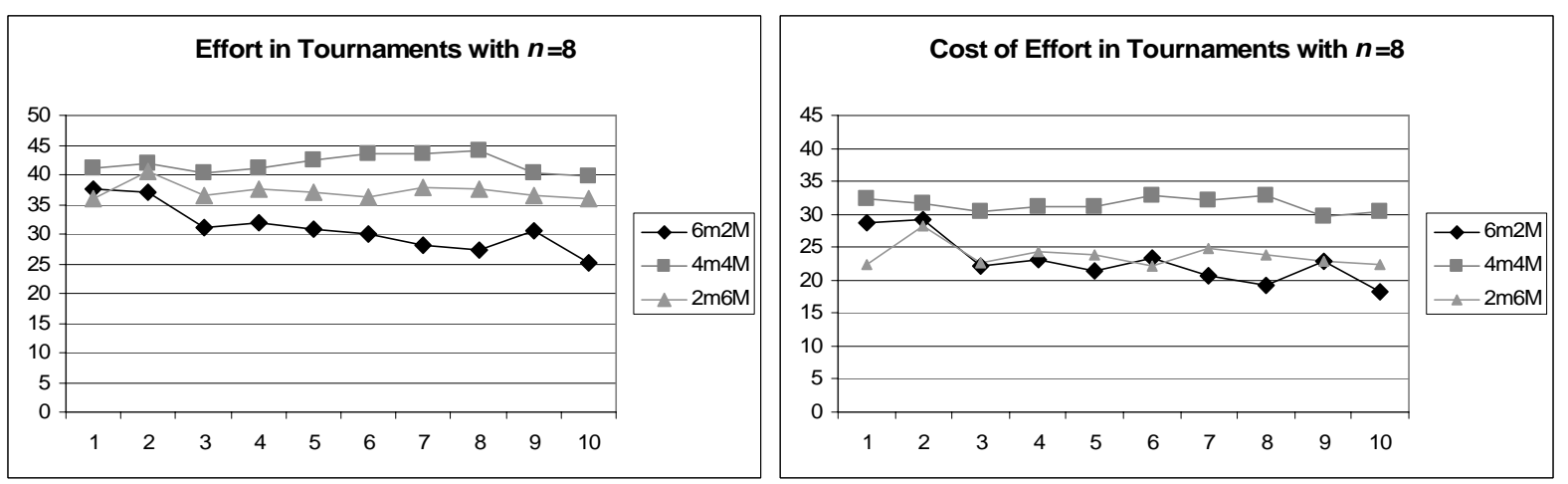

Figure 2: Average efforts and resulting costs over rounds in eight-person tournaments. The figure shows averages over two consecutive rounds. 
Table 4 depicts the results of the statistical analysis and confirms the visual impression that productive effort is highest - although not always significant - in tournaments with an equal distribution of winner and loser prizes.

Table 4: Statistical comparison of the treatments regarding the fraction of winner prizes

\begin{tabular}{|c|c|c|c|c|c|c|}
\hline & \multicolumn{6}{|c|}{ comparison of treatments } \\
\hline & \multicolumn{3}{|c|}{4 agents } & \multicolumn{3}{|c|}{8 agents } \\
\hline & $\begin{array}{l}\text { 3m1M } \\
\text { and }\end{array}$ & $\begin{array}{c}\text { 2m2M } \\
\text { and }\end{array}$ & $\begin{array}{c}\text { 3m1M } \\
\text { and }\end{array}$ & $\begin{array}{l}\text { 6m2M } \\
\text { and }\end{array}$ & $\begin{array}{c}\text { 4m4M } \\
\text { and }\end{array}$ & $\begin{array}{c}\text { 6m2M } \\
\text { and }\end{array}$ \\
\hline & $2 \mathrm{~m} 2 \mathrm{M}$ & $1 \mathrm{~m} 3 \mathrm{M}$ & $1 \mathrm{~m} 3 \mathrm{M}$ & $4 \mathrm{~m} 4 \mathrm{M}$ & $2 \mathrm{~m} 6 \mathrm{M}$ & $2 \mathrm{~m} 6 \mathrm{M}$ \\
\hline \multicolumn{7}{|l|}{ average activities } \\
\hline effort & $<* * *$ & $>$ & $<$ & $<* * *$ & $>$ & $<*$ \\
\hline sabotage & $>$ & $<$ & $>$ & $<*$ & $>$ & $<$ \\
\hline \multicolumn{7}{|l|}{ average costs of agents for } \\
\hline effort & $<* *$ & $>$ & $<$ & $<* *$ & $>* *$ & $<$ \\
\hline sabotage & $>$ & $<$ & $>$ & $<$ & $>$ & $>$ \\
\hline \multicolumn{7}{|l|}{ standard deviation over rounds for } \\
\hline effort & $>$ & $>*$ & $>* *$ & $<$ & $>* * *$ & $>* * *$ \\
\hline sabotage & $>$ & $>*$ & $>* *$ & $>$ & $>$ & $>* * *$ \\
\hline average output per agent & $<* *$ & $>$ & $<$ & $>$ & $<$ & $>$ \\
\hline $\begin{array}{l}\text { median ratio of costs of effort and } \\
\text { sabotage }\end{array}$ & $<* *$ & $>$ & $<$ & $<$ & $<$ & $<* *$ \\
\hline $\begin{array}{l}\text { average ratio of marginal costs of effort } \\
\text { and sabotage }\end{array}$ & $<*$ & $>$ & $<$ & $<$ & $<$ & $<$ \\
\hline
\end{tabular}

By using the Mann-Whitney $U$ test we state the level of significance at which the null hypothesis that there is no difference between the average observations from both treatments can be rejected in favor of the alternative hypothesis that average values are higher (lower) in one treatment than the other. The test is conducted as a twotailed test.

$\begin{array}{lll}* & \text { weakly significant: } & 0.05<\alpha \leq 0.10 \\ * * & \text { significant: } & 0.01<\alpha \leq 0.05 \\ * * * & \text { highly significant: } & \alpha \leq 0.01\end{array}$

This is also reflected by the comparison of the average cost of effort (see Table 5 for an overview of costs of effort and sabotage). Moreover, $\lambda=1 / 2$ is the only winner prize fraction where effort is always significantly above the equilibrium level (see Table 3). 
Table 5: Overview of experimental results regarding effort costs and sabotage costs

\begin{tabular}{|c|c|c|c|c|c|c|c|}
\hline & \multicolumn{7}{|c|}{ treatments } \\
\hline & $1 \mathrm{~m} 1 \mathrm{M}$ & $3 \mathrm{~m} 1 \mathrm{M}$ & $2 \mathrm{~m} 2 \mathrm{M}$ & $1 \mathrm{~m} 3 \mathrm{M}$ & $6 \mathrm{~m} 2 \mathrm{M}$ & $4 \mathrm{~m} 4 \mathrm{M}$ & $2 \mathrm{~m} 6 \mathrm{M}$ \\
\hline tournament size $n$ & 2 agents & & 4 agents & & & 8 agents & \\
\hline fraction of winner prizes $\lambda$ & $1 / 2$ & $1 / 4$ & $1 / 2$ & $3 / 4$ & $1 / 4$ & $1 / 2$ & $3 / 4$ \\
\hline average cost of effort & 32.92 & 23.10 & 34.71 & 24.76 & 22.86 & 31.45 & 23.72 \\
\hline $\begin{array}{l}\text { cost of effort in } \\
\text { equilibrium }\end{array}$ & 13.33 & 13.33 & 13.33 & 13.33 & 13.33 & 13.33 & 13.33 \\
\hline average cost of sabotage & 19.75 & 18.01 & 12.30 & 12.63 & 13.58 & 17.51 & 12.70 \\
\hline $\begin{array}{l}\text { cost of sabotage in } \\
\text { equilibrium }\end{array}$ & 3.33 & 3.33 & 3.33 & 3.33 & 3.33 & 3.33 & 3.33 \\
\hline $\begin{array}{l}\text { median ratio of costs of } \\
\text { effort and sabotage }\end{array}$ & 1.73 & 1.43 & 2.39 & 1.91 & 1.16 & 2.18 & 2.25 \\
\hline $\begin{array}{l}\text { average ratio of marginal } \\
\text { costs of effort and } \\
\text { sabotage }\end{array}$ & 0.73 & 0.64 & 0.94 & 0.79 & 0.71 & 0.75 & 0.77 \\
\hline
\end{tabular}

So far only aggregated behavior has been analyzed. Behavior of individuals, however, may differ among groups. One interesting question is whether some individuals persistently drop out of the contest or overexert effort and sabotage. Examples for such an extreme behavior are found in contests by MÜLLER and SCHOTTER (2003) as well as in a different tournament setting without sabotage by HARBRING and IRLENBUSCH (2003 a). Table 6 depicts the average individual activities ranked by effort and sabotage, i.e., the average activity levels of individuals in each group are ranked and the average of all individuals with the same rank is given across groups. 
Table 6: Results on average individual activities ranked by effort and sabotage

\begin{tabular}{|c|c|c|c|c|c|c|c|}
\hline \multirow{3}{*}{$\begin{array}{c}\text { treatments } \\
1 \mathrm{~m} 1 \mathrm{M}\end{array}$} & \multirow{3}{*}{$\begin{array}{l}\text { tournament } \\
\text { size } n \\
2\end{array}$} & \multirow{3}{*}{$\begin{array}{c}\text { fraction of } \\
\text { winner } \\
\text { prizes } \lambda\end{array}$} & \multirow{3}{*}{$\begin{array}{c}\text { rank } \\
\\
1 \\
2\end{array}$} & \multicolumn{2}{|c|}{$\begin{array}{l}\text { effort averaged over } \\
\text { individuals with same } \\
\text { effort rank }\end{array}$} & \multicolumn{2}{|c|}{$\begin{array}{l}\text { sabotage averaged over } \\
\text { individuals with same } \\
\text { sabotage rank }\end{array}$} \\
\hline & & & & 32.03 & {$[12.82]^{*}$} & 8.76 & {$[37.84]^{* *}$} \\
\hline & & & & 53.68 & [16.43] & 20.49 & [47.87] \\
\hline \multirow{4}{*}{$3 \mathrm{~m} 1 \mathrm{M}$} & \multirow{4}{*}{4} & \multirow{4}{*}{$1 / 4$} & 1 & 11.54 & [4.58] & 1.73 & [17.44] \\
\hline & & & 2 & 27.40 & [11.93] & 8.16 & [33.68] \\
\hline & & & 3 & 34.98 & [15.88] & 16.45 & [29.53] \\
\hline & & & 4 & 55.03 & [17.69] & 23.74 & [48.30] \\
\hline \multirow{4}{*}{$2 \mathrm{~m} 2 \mathrm{M}$} & \multirow{4}{*}{4} & \multirow{4}{*}{$1 / 2$} & 1 & 19.46 & [6.44] & 3.89 & [27.83] \\
\hline & & & 2 & 39.28 & [14.06] & 9.56 & [53.73] \\
\hline & & & 3 & 50.33 & [12.16] & 13.83 & [46.53] \\
\hline & & & 4 & 66.90 & [13.75] & 19.14 & [47.88] \\
\hline \multirow{4}{*}{$1 \mathrm{~m} 3 \mathrm{M}$} & \multirow{4}{*}{4} & \multirow{4}{*}{$3 / 4$} & 1 & 25.66 & [13.51] & 4.33 & [37.65] \\
\hline & & & 2 & 32.04 & [13.36] & 9.13 & [41.99] \\
\hline & & & 3 & 40.84 & [9.84] & 14.97 & [41.45] \\
\hline & & & 4 & 54.74 & [11.11] & 19.40 & [32.19] \\
\hline \multirow{8}{*}{$6 \mathrm{~m} 2 \mathrm{M}$} & \multirow{8}{*}{8} & \multirow{8}{*}{$1 / 4$} & 1 & 5.98 & [5.18] & 0.73 & [17.18] \\
\hline & & & 2 & 10.99 & [3.71] & 2.95 & [15.53] \\
\hline & & & 3 & 15.51 & [5.98] & 5.13 & [24.42] \\
\hline & & & 4 & 22.49 & [11.16] & 7.33 & [38.71] \\
\hline & & & 5 & 37.44 & [13.63] & 10.54 & [24.74] \\
\hline & & & 6 & 43.44 & [12.28] & 13.99 & [41.36] \\
\hline & & & 7 & 50.48 & [13.93] & 18.12 & [39.41] \\
\hline & & & 8 & 60.89 & [17.03] & 24.10 & [45.89] \\
\hline \multirow{8}{*}{$4 \mathrm{~m} 4 \mathrm{M}$} & \multirow{8}{*}{8} & \multirow{8}{*}{$1 / 2$} & 1 & 11.77 & [9.24] & 3.41 & [25.19] \\
\hline & & & 2 & 24.41 & [13.75] & 6.21 & [41.61] \\
\hline & & & 3 & 31.74 & [14.53] & 9.54 & [36.85] \\
\hline & & & 4 & 39.70 & [11.88] & 10.71 & [48.09] \\
\hline & & & 5 & 48.14 & [11.14] & 14.39 & [40.84] \\
\hline & & & 6 & 51.44 & [17.49] & 17.39 & [48.68] \\
\hline & & & 7 & 56.61 & [18.66] & 21.79 & [45.98] \\
\hline & & & 8 & 70.49 & [14.33] & 27.59 & [47.05] \\
\hline \multirow{8}{*}{$2 \mathrm{~m} 6 \mathrm{M}$} & \multirow{8}{*}{8} & \multirow{8}{*}{$3 / 4$} & 1 & 14.57 & [6.84] & 1.21 & [26.85] \\
\hline & & & 2 & 25.30 & [7.28] & 5.19 & [30.13] \\
\hline & & & 3 & 29.08 & [12.53] & 8.09 & [31.68] \\
\hline & & & 4 & 36.29 & [13.94] & 10.86 & [44.18] \\
\hline & & & 5 & 39.31 & [13.33] & 13.05 & [39.70] \\
\hline & & & 6 & 44.23 & [12.21] & 15.19 & [42.03] \\
\hline & & & 7 & 49.09 & [13.02] & 18.37 & [43.29] \\
\hline & & & 8 & 59.54 & [16.88] & 24.06 & [39.55] \\
\hline
\end{tabular}

$\overline{\text { Average individual activities ranked by effort and sabotage, i.e., the average activity levels of individuals in each }} \overline{\bar{y}} \overline{\bar{c}} \overline{\bar{c}}$ group are ranked and the average of all individuals with the same rank is given across groups.

${ }^{*}$ The value in square brackets gives the corresponding amount of sabotage averaged over the same players who exerted the effort on that rank position.

** The value in square brackets gives the corresponding amount of effort averaged over the same players who exerted the sabotage on that rank position.

We find that in tournaments with $\lambda=1 / 4$ a slightly higher proportion of individuals seems to choose average effort levels below the level predicted by theory. ${ }^{8}$ On the other hand, Table 6 indicates that some players persistently oversupply effort. The average effort of those max- 
performers, i.e., the average effort of the individuals who exert the highest average effort in each group, tends to be highest in the treatment with $\lambda=1 / 2$ (compare also Table 8). The values in square brackets in Table 6 give the average activity level of the same player regarding the other kind of activity. Apparently, participants tend to have similar ranks regarding the exertion of both activity levels.

Table 7 supplies a more detailed analysis of the frequency of non-participants, i.e., participants who completely drop out of the competition by exerting the minimal effort or/and sabotage activity of zero.

Table 7: Frequency of non-participants per player and round (in \%)

\begin{tabular}{cccc|c|c}
\hline \hline treatments & $\begin{array}{c}\text { tournament } \\
\text { size } n\end{array}$ & $\begin{array}{c}\text { fraction of } \\
\text { winner } \\
\text { prizes } \lambda\end{array}$ & $\begin{array}{c}\text { non-participants } \\
\text { regarding effort } \\
\text { (in \%) }\end{array}$ & $\begin{array}{c}\text { non-participants } \\
\text { regarding sabotage } \\
\text { (in \%) }\end{array}$ & $\begin{array}{c}\text { non-participants regarding } \\
\text { effort and sabotage in } \\
\text { same round (in \%) }\end{array}$ \\
\hline $1 \mathrm{~m} 1 \mathrm{M}$ & 2 & $1 / 2$ & 17.75 & 31.00 & 17.50 \\
\hline $3 \mathrm{~m} 1 \mathrm{M}$ & 4 & $1 / 4$ & 25.63 & 34.53 & 24.06 \\
\hline $2 \mathrm{~m} 2 \mathrm{M}$ & 4 & $1 / 2$ & 10.63 & 21.88 & 9.06 \\
\hline $1 \mathrm{~m} 3 \mathrm{M}$ & 4 & $3 / 4$ & 7.50 & 21.43 & 6.00 \\
\hline $6 \mathrm{~m} 2 \mathrm{M}$ & 8 & $1 / 4$ & 28.67 & 37.97 & 25.86 \\
\hline $4 \mathrm{~m} 4 \mathrm{M}$ & 8 & $1 / 2$ & 14.53 & 21.95 & 13.05 \\
\hline $2 \mathrm{~m} 6 \mathrm{M}$ & 8 & $3 / 4$ & 7.19 & 15.63 & 9.06 \\
\hline \hline
\end{tabular}

For a given tournament size the frequency of non-participants in each round seems to decrease with an increasing number of winner prizes. This is in line with the results by HARBRING and IRLENBUSCH (2003 a) who also find - in a different tournament setting without sabotage - that the number of non-participants is decreasing with an increasing fraction of winner prizes. Interestingly, Table 7 also shows that participants who exert an effort of zero often also exert a sabotage activity of zero. Thus, those participants really refrain from actively participating in the contest by choosing minimal activity levels. Note that such behavior could also be due to collusion among participants. However, we find no indication of systematic collusive behavior in any of the groups. Table 8 supplies the statistical results of a comparison of non-participants and max-performers.

\footnotetext{
8 The number of individual effort choices in each group below the equilibrium level is significantly larger in tournaments with $\lambda=1 / 4$ than with $\lambda=1 / 2$ (3m1M vs. $2 \mathrm{~m} 2 \mathrm{M}: \alpha=0.050,6 \mathrm{~m} 2 \mathrm{M}$ vs. $4 \mathrm{~m} 4 \mathrm{M}: \alpha=0.000$, MannWhitney U test, two-tailed).
} 
Table 8: Statistical comparison of the treatments regarding non-participants and maxperformers

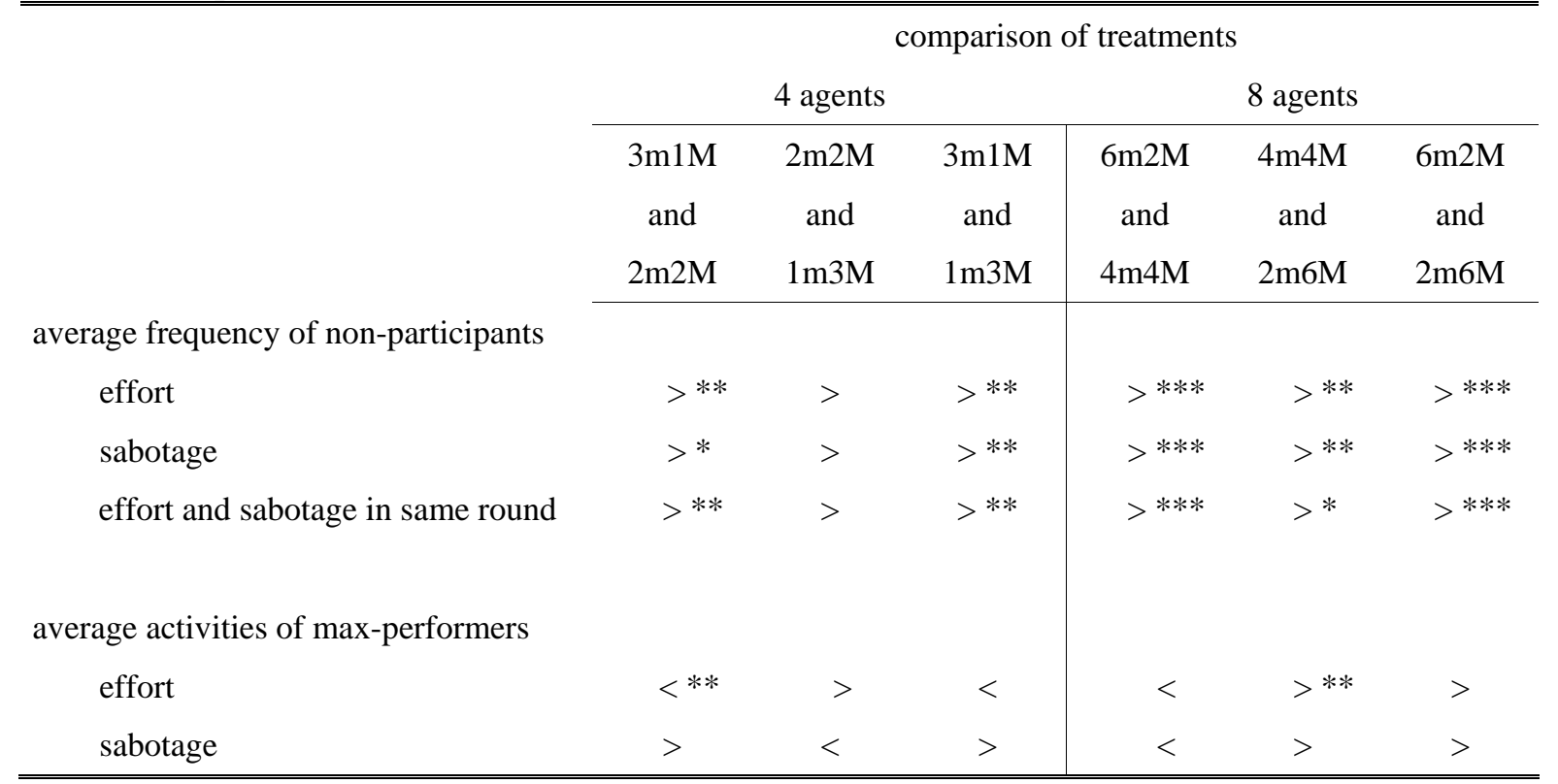

By using the Mann-Whitney U test we state the level of significance at which the null hypothesis that there is no difference between the average observations from both treatments can be rejected in favor of the alternative hypothesis that average values are higher (lower) in one treatment than the other. The test is conducted as a twotailed test.

$\begin{array}{lll}* & \text { weakly significant: } & 0.05<\alpha \leq 0.10 \\ * * & \text { significant: } & 0.01<\alpha \leq 0.05 \\ * * * & \text { highly significant: } & \alpha \leq 0.01\end{array}$

The results show that the number of non-participants is significantly highest in tournaments with $\lambda=1 / 4$. In eight-person tournaments we even observe that the number of non-participants is significantly decreasing with an increasing fraction of winner prizes. Moreover, we find weak support for the assumption that the average effort of the max-performers is highest in tournaments with as many winner prizes as loser prizes.

\section{ii) Sabotage}

Behavior regarding the sabotage activity appears to be only weakly in line with the findings on productive effort (see also Figures 3 and 4). In eight-person tournaments a significant difference in sabotage between $6 \mathrm{~m} 2 \mathrm{M}$ and $4 \mathrm{~m} 4 \mathrm{M}$ is found (see Table 4). However, no difference between average costs of sabotage is observed. As in the case with effort $\lambda=1 / 2$ is the only winner prize fraction where sabotage is always significantly above the equilibrium level. 

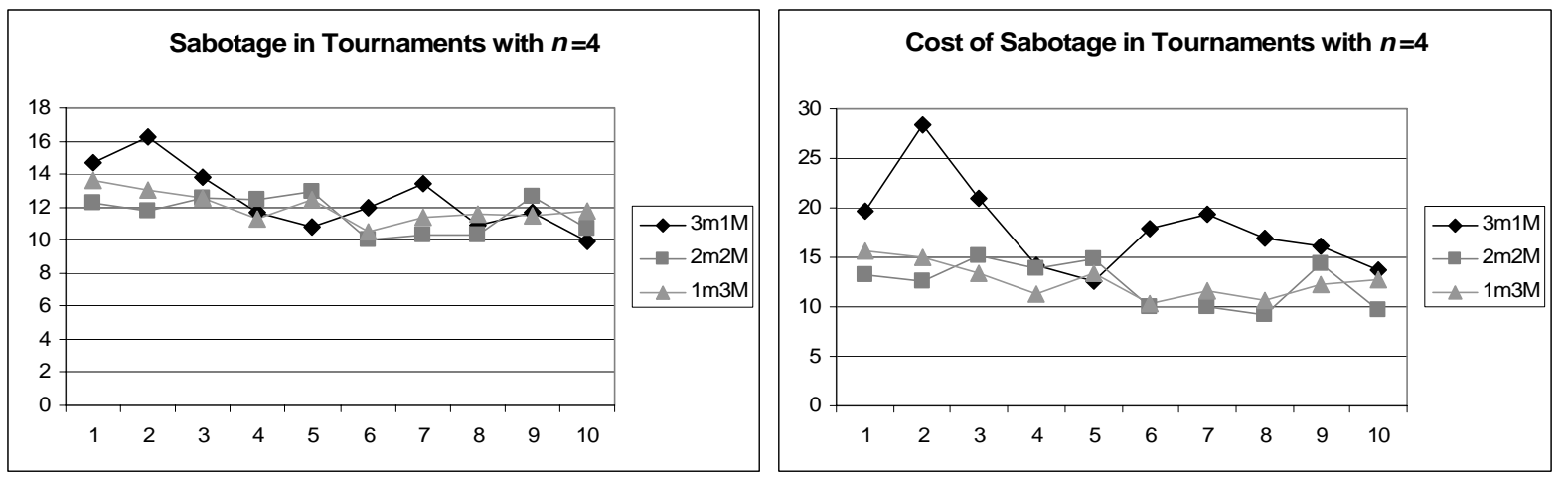

Figure 3: Average sabotage activities and resulting costs over rounds in four-person tournaments. The figure shows averages over two consecutive rounds.
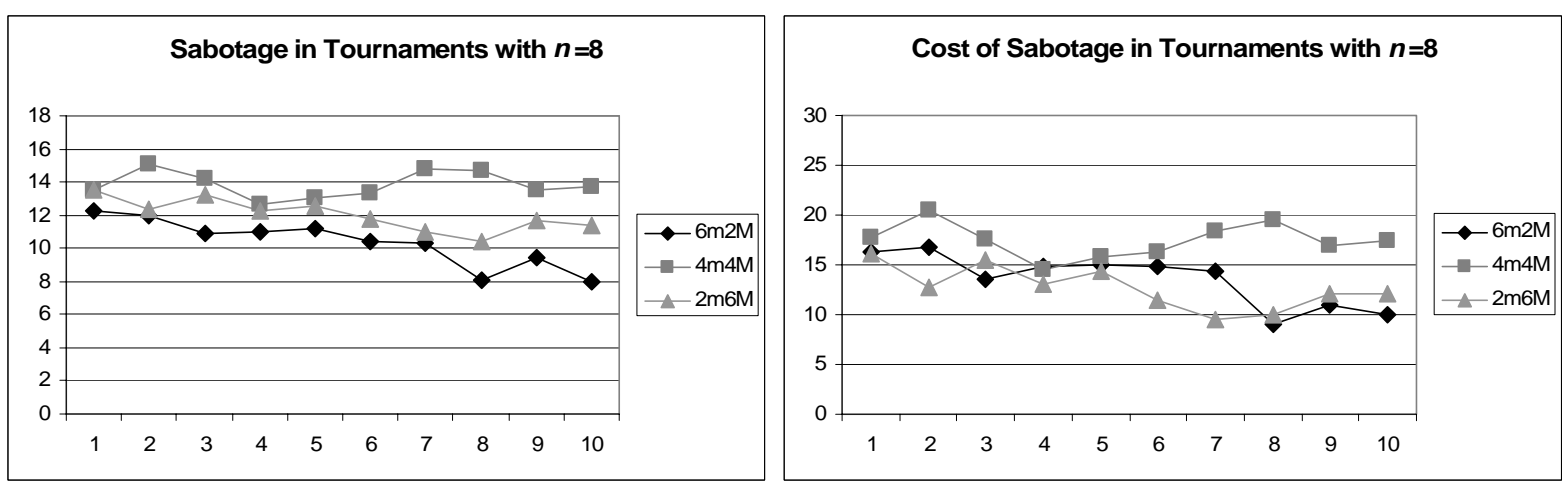

Figure 4: The average sabotage activities and resulting costs over rounds in eight-person tournaments. The figure shows averages over two consecutive rounds.

A detailed analysis regarding individual sabotage behavior roughly corresponds to the results on the productive activity. The frequency of non-participants tends to decrease with an increasing fraction of winner prizes. ${ }^{9}$ Table 7 shows that much more participants exert a sabotage activity of zero than an effort of zero (3m1M: $\alpha=0.016,2 \mathrm{~m} 2 \mathrm{M}: \alpha=0.016,1 \mathrm{~m} 3 \mathrm{M}$ : $\alpha=0.031,6 \mathrm{~m} 2 \mathrm{M}: \alpha=0.008,4 \mathrm{~m} 4 \mathrm{M}: \alpha=0.063,2 \mathrm{~m} 6 \mathrm{M}: \alpha=0.063$, Wilcoxon Signed Rank test, two-tailed). Participants exerting an effort of zero also often refrain from exerting sabotage and thus drop completely out of the competition. Finally, we find no statistical support for the finding that the sabotage activity of max-performers is highest in tournaments with $\lambda=1 / 2$ (see Table 8).

\section{iii) Effort and Sabotage}

After analyzing productive and destructive activities separately it is essential to bring the effect of both activities together in order to find out whether the variation of one activity may

\footnotetext{
${ }^{9}$ Moreover, the number of individual sabotage choices in each group below the equilibrium level is significantly larger in eight-person tournaments with $\lambda=1 / 4$ than with $\lambda=1 / 2$ and $\lambda=3 / 4(6 \mathrm{~m} 2 \mathrm{M}$ vs. $4 \mathrm{~m} 4 \mathrm{M}: \alpha=0.028,6 \mathrm{~m} 2 \mathrm{M}$ vs. $2 \mathrm{~m} 6 \mathrm{M}$ : $\alpha=0.000$, Mann-Whitney U test, two-tailed).
} 
overcompensate the other. This is done by investigating the average output (see Table 3) and also the ratio of costs of effort and sabotage as well as the ratio of marginal costs of effort and sabotage (see Table 5).

If agents would be rational and exclusively be interested in their own well-being they essentially face only one strategic decision: How much to spend in total on effort and sabotage. Recall that exerting one unit of effort or exerting one unit of sabotage has the same effect on the own rank position in the tournament. Thus, the relation between cost for effort and cost for sabotage completely determines the optimal distribution of how much effort and sabotage to exert. Indeed, according to the experimental parameters agents should always allocate 20 percent of the cost on sabotage and 80 percent on productive effort while the ratio of the marginal costs of sabotage and effort should be equal to $1 .{ }^{10}$ Interestingly, this is not what we observe. In fact the ratios of costs of effort and sabotage are well below 4 while correspondingly the ratios of marginal costs of effort and sabotage are lower than 1 in all of the treatments. Thus, agents exert too much sabotage in relation to productive effort.

Regarding the ratio of both activities only one difference for all three measures can be found between treatments at a conventional significance level: The average output per agent, the median ratio of costs as well as the average ratio of marginal costs of effort and sabotage in $2 \mathrm{~m} 2 \mathrm{M}$ is significantly higher than in $3 \mathrm{~m} 1 \mathrm{M}$ (Table 4 ). This is apparently due to the productive effort being larger in the treatment with $\lambda=1 / 2$.

Finally, from an employer's perspective it is essential to know whether additional wage costs incurred by more winner prizes pay off in terms of additional output, e.g., resulting from an increase in productive effort. Table 3 shows that for a given tournament size additional output is only produced if one shifts from $3 \mathrm{~m} 1 \mathrm{M}$ to $2 \mathrm{~m} 2 \mathrm{M}$ or $1 \mathrm{~m} 3 \mathrm{M}$ and from $4 \mathrm{~m} 4 \mathrm{M}$ to $2 \mathrm{~m} 6 \mathrm{M}$. If an employer changes the tournament scheme from $3 \mathrm{~m} 1 \mathrm{M}$ to $2 \mathrm{~m} 2 \mathrm{M}$ by increasing the number of winner prizes by one, he has to pay 1.72 Talers for one additional unit of output while he has to pay 2.94 Talers when changing from $4 \mathrm{~m} 4 \mathrm{M}$ to $2 \mathrm{~m} 6 \mathrm{M}$. .The shift from $3 \mathrm{~m} 1 \mathrm{M}$ to $1 \mathrm{~m} 3 \mathrm{M}$ is dominated by the shift from $3 \mathrm{~m} 1 \mathrm{M}$ to $2 \mathrm{~m} 2 \mathrm{M}$ in terms of additional costs per unit of output. Note that in the eight-person tournaments output is improved but is still negative. Whether these changes to a new reward structure pay off economically for the employer depends on the external value assigned to one output unit which is not modeled in our framework. Note that our compensation scheme for the principal as a manager includes a bonus proportional to

\footnotetext{
10 Note that the comparison of the marginal cost ratios also reflects the ratio of the absolute amount of effort exerted per unit of sabotage: $\left(\partial C_{e}\left(e_{i}\right) / \partial e_{i}\right) /\left(\partial C_{s}\left(s_{i}\right) / \partial s_{i}\right)=\left(2 e_{i} / c_{e}\right) /\left(2 s_{i} / c_{s}\right)=e_{i} / 4 s_{i}$ as the ratio of cost parameters is $c_{e}=4 c_{s}$ We compute the ratio of marginal costs by dividing the average values of each independent observation.
} 
the output indicated by the factor $\tau$, which in general can assumed to be smaller than the total value of one output unit.

\subsection{Development of Behavior over Rounds}

An employer who implements a tournament among employees is also interested in the variability of the induced activity as its variation is an indicator for the reliability of the incentive effect. Table 3 depicts the average standard deviation of effort and sabotage activities exerted over rounds. The comparison between treatments is summarized by Table 4 . The variation of both activity dimensions is lowest in the treatments with the highest fraction of winner prizes, i.e., with $\lambda=3 / 4$. Thus, a low variability of activities is likely to be induced by distributing many winner prizes.

Figures 1 - 4 already indicate that behavior changes over rounds. Therefore, in Table 9 we aggregate behavior for the first part of the experiment, i.e., the first ten rounds, and the second part, i.e., the second ten rounds.

Table 9: Significant differences of activities between first ten rounds (part I) and second ten rounds (part II)

\begin{tabular}{|c|c|c|c|c|c|c|c|}
\hline effort & $\begin{array}{c}\text { part I } \\
\text { (round 1-10) }\end{array}$ & & $\begin{array}{c}\text { part II } \\
\text { (round 11-20) }\end{array}$ & sabotage & $\begin{array}{c}\text { part I } \\
\text { (round 1-10) }\end{array}$ & & $\begin{array}{c}\text { part II } \\
\text { (round 11-20) }\end{array}$ \\
\hline $1 \mathrm{~m} 1 \mathrm{M}$ & 44.12 & $>$ & 41.59 & $1 \mathrm{~m} 1 \mathrm{M}$ & 16.28 & $>* * *$ & 12.98 \\
\hline $3 \mathrm{~m} 1 \mathrm{M}$ & 33.23 & $>$ & 31.25 & $3 \mathrm{~m} 1 \mathrm{M}$ & 13.46 & $>* *$ & 11.58 \\
\hline $2 \mathrm{~m} 2 \mathrm{M}$ & 46.08 & $>$ & 41.91 & $2 \mathrm{~m} 2 \mathrm{M}$ & 12.39 & $>*$ & 10.82 \\
\hline $1 \mathrm{~m} 3 \mathrm{M}$ & 40.51 & $>$ & 36.13 & $1 \mathrm{~m} 3 \mathrm{M}$ & 12.58 & $>$ & 11.34 \\
\hline $6 \mathrm{~m} 2 \mathrm{M}$ & 33.61 & $>* *$ & 28.20 & $6 \mathrm{~m} 2 \mathrm{M}$ & 11.49 & $>*$ & 9.23 \\
\hline $4 \mathrm{~m} 4 \mathrm{M}$ & 41.33 & $<$ & 42.24 & $4 \mathrm{~m} 4 \mathrm{M}$ & 13.73 & $<$ & 14.03 \\
\hline $2 \mathrm{~m} 6 \mathrm{M}$ & 37.55 & $>$ & 36.80 & $2 \mathrm{~m} 6 \mathrm{M}$ & 12.77 & $>* *$ & 11.23 \\
\hline
\end{tabular}

By using the Wilcoxon Signed Rank test we state the level of significance at which the null hypothesis that there is no difference between the average observations from both parts of each treatment can be rejected in favor of the alternative hypothesis that average values are higher (lower) in one part than the other. The test is conducted as a two-tailed test.

$\begin{array}{lll}* & \text { weakly significant: } & 0.05<\alpha \leq 0.10 \\ * * & \text { significant: } & 0.01<\alpha \leq 0.05 \\ * * * & \text { highly significant: } & \alpha \leq 0.01\end{array}$

We find that effort is significantly lower in the second part of the experiment in $6 \mathrm{~m} 2 \mathrm{M}$. A more detailed analysis reveals that only the average effort which results in obtaining the loser prize is significantly lower in the second part of $6 \mathrm{~m} 2 \mathrm{M}$ than in the first part. Moreover, the sabotage activities in the second part are significantly lower than those in the first part in 
almost all of the treatments. Similar to the result on effort in $6 \mathrm{~m} 2 \mathrm{M}$ the decrease of the sabotage activity is mainly due to a decrease of sabotage by those agents who obtain the loser prize. In $2 \mathrm{~m} 6 \mathrm{M}$ it is due to a decrease of sabotage by agents who receive the winner prize. Figures $1-4$ provide the impression that the effect due to the fraction of winner prizes is decreasing over the rounds in four-person tournaments and increasing in eight-person tournaments. This finding can only weakly be confirmed by a comparison of both parts in each treatment. $^{11}$

\section{Discussion of Results}

We find only weak effects due to a variation of tournament size. Thus, our results are in line with the findings of ORRISON, SCHOTTER, and WEIGELT (2004) who also state that tournament size has no essential impact on effort.

The effect of the fraction of winner prizes is more pronounced. We find that productive effort seems to be highest in treatments with a balanced fraction of winner and loser prizes. Regarding individual behavior some participants seem to supply very high efforts in tournaments with as many winner as loser prizes. ORRISON, SCHOTTER, and WEIGELT (2004) state an observation which goes into the same direction. They find that effort is lower in tournaments with a fraction of winner prizes of $2 / 3$ than in treatments with $1 / 2$ and $1 / 3$. The different fractions of winner prizes we implement in our design are more extreme. Thus, this might explain why we find an additional effect if the fraction of winner prizes is low.

Given our observations we conjecture - similar to ORRISON, SCHOTTER, and WEIGELT (2004) - that agents do not condition their behavior on the (constant) marginal probability of winning as the theoretic analysis suggests. One possible explanation which is in line with our findings is offered by ATKINSON (1958) in his achievement motivation theory. According to this theory from psychology the achievement motive is "conceived as a capacity for taking pride in accomplishment when success at one or another activity is achieved"(ATKINSON 1984, p. 241). Intuitively, his theory suggests that a task with a subjectively expected probability of success of $1 / 2$ is perceived as particularly motivating. In tournaments with a low fraction of winner prizes the subjective winning probability is low while the challenge is large. In tournaments with a high fraction of winner prizes the expectancy of success is high but the

\footnotetext{
11 The most important differences are as follows: Average effort is significantly higher in $4 \mathrm{~m} 4 \mathrm{M}$ than in $6 \mathrm{~m} 2 \mathrm{M}$ in the first part of the experiment (Mann-Whitney U test: $\alpha=0.05$, two-tailed) while in the second part subjects exert higher efforts in $4 \mathrm{~m} 4 \mathrm{M}$ than in both other treatments (Mann-Whitney U test: $4 \mathrm{~m} 4 \mathrm{M}$ vs. $6 \mathrm{~m} 2 \mathrm{M} \alpha=0.000$, $4 \mathrm{~m} 4 \mathrm{M}$ vs. $2 \mathrm{~m} 6 \mathrm{M} \alpha=0.083$, two-tailed). Regarding the sabotage activity no difference can be found regarding part I. In part II, however, sabotage is significantly lower in $6 \mathrm{~m} 2 \mathrm{M}$ than in $4 \mathrm{~m} 4 \mathrm{M}$ (Mann-Whitney U test: $6 \mathrm{~m} 2 \mathrm{M}$ vs. $4 \mathrm{~m} 4 \mathrm{M} \alpha=0.05$, two-tailed).
} 
challenge is relatively low. ${ }^{12}$ We find hints to the fact that particularly the productive effort is highest if the number of winner and loser prizes is balanced which might be explained by the achievement motivation theory. However, this explanation remains an ex post speculation and further research is needed to unambiguously support the predictive power of ATKINSON's theory in this tournament setting. Additional clarification might also be gained from the concept of vulnerability proposed by NALBANTIAN and SCHOTTER (1994) and SCHOTTER (1996). The concept of vulnerability takes into account how fast an equilibrium payoff of an agent would fall if others deviated from the equilibrium effort levels. Interestingly, one can show that agents in our setting are more vulnerable if the number of winner and loser prizes is balanced, i.e., the reduction of an individual's payoff elicited by all feasible combinations of other agents' increases of effort is highest in tournaments if there are as many winner as loser prizes. ${ }^{13}$ Apparently, this leads agents to exert higher effort levels. This observation and its interpretation, however, have to be left to further research in order to clarify the corresponding underlying behavioral mechanisms.

For instance it remains an open question why sabotaging behavior cannot easily be explained by a similar argumentation. The amount of sabotage appears to be relatively constant between treatments. Taking a closer look at the results we find two different behavioral patterns regarding the sabotage activity. On the one hand agents might be guided by efficiency considerations (for evidence in this line see for example CHARNESS and RABIN 2002), i.e., they seem to keep their sabotage below a certain threshold because, e.g., each unit of sabotage reduces the principal's as well as the agent's payoff. Indeed, we find that much more participants exert a sabotage activity of zero than an effort of zero. On the other hand, we also find that the ratios of costs of effort and sabotage as well as the ratios of marginal costs of effort and sabotage clearly differ from our theoretical prediction. On average participants seem to exert inefficiently high sabotage activities compared to the level of productive activities although there is no strategic reason for agents to do so. We can only conjecture that agents might be inclined to reduce the payoff difference between themselves and the principal by exerting such an inefficiently high amount of sabotage. Such an explanation would be in line with agents tending to have a preference for inequity aversion (FEHR and SCHMIDT 1999).

\footnotetext{
12 Note that also the variance of tournament prizes is maximal for a fraction of winner prizes of $\lambda=1 / 2$. Thus, the hypothesis can also be interpreted as follows: the "uncertainty" under which one obtains a prize is largest if there are as many winner as loser prizes. This might be perceived as particularly motivating. The variance of tournament prizes is: $\sigma^{2}=\lambda(m+\Delta-(m+\lambda \Delta))^{2}+(1-\lambda)(m-(m+\lambda \Delta))^{2}=\Delta^{2} \lambda(1-\lambda)$.

13 A more elaborated analysis can be obtained upon request from the authors.
} 
At least in the treatments with $n=4$ and $n=8$ in equilibrium the payoff of the principal is higher than the payoffs of the agents. By exerting higher sabotage (up to a moderate level) the agents can indeed reduce the payoff difference since the additional sabotage cost they have to bear is lower than the reduction of total output and thereby harms the principal's payoff to a greater extent than their own payoff. Thus, our results suggest that participants seem to be driven by efficiency considerations as well as by inequity aversion.

Our finding that the variability of activities from both dimensions is lowest for a high fraction of winner prizes emphasizes an earlier result obtained in a related study (see HARBRING and IRLENBUSCH 2003 a). Agents might be encouraged by receiving winner prizes on average more often, and do not vary their activities frequently but stick to a certain activity level. This is in line with the finding that the frequency of non-participants decreases with an increasing fraction of winner prizes. If the fraction is low participants seem to perceive the probability of winning one of the high prizes as low and drop out of the contest.

Particularly, the sabotage activities are lower in the second part of the experiment than in the first part. One might interpret this result as a learning process which induces participants to approach the equilibrium level. Note, however, that we cannot decide whether the development of behavior over rounds is due to experience or a form of strategic behavior, e.g. participants might start with higher activities in early rounds to discourage other players such that they refrain from high activity levels in later rounds. To differentiate between both explanations a restart procedure could be used, i.e., the experiment is restarted after a certain number of rounds which is unknown to the subjects during the first part (see e.g. CoOKSON 2000). Such a restart procedure is implemented in tournaments without sabotage by HARBring and IrLEnBusch (2003 a) and HARBring and Ruchala (2005). They do not find any systematic effect due to the restart procedure and conclude that learning rather than strategic considerations drives agents' behavior in tournaments.

\section{Conclusion}

Relative performance evaluation suffers from a severe drawback that is analyzed in this study: Agents may deteriorate the other agents' performance to improve the own relative position, i.e., they can sabotage each other. Sabotage is forbidden in real-world organizations, and as a consequence data on sabotage can barely be collected. Therefore, we approach our analysis by a controlled laboratory experiment to gain a deeper understanding of this economic problem. An experimental study of a simple tournament model with two activity dimensions is employed: A productive and a destructive activity (i.e., sabotage). Agents compete for 
attaining one of the winner prizes by exerting productive effort and sabotage. The latter reduces the output of all other agents in their group.

We analyze the influence of tournament size and the fraction of winner prizes. Tournament size is particularly interesting in this context as the destructive effect of sabotage increases with the number of participants. Thus, in large tournaments sabotage activities overcompensate the productive efforts. From a theoretic perspective both design alternatives have no impact on participants' behavior in equilibrium.

First of all, our results from the laboratory confirm that sabotage happens as predicted by the underlying model. Secondly, we find that tournament size has in fact no essential effect on the behavior of participants which is also in line with our theoretic prediction. Finally, our results indicate that in particular productive activities appear to be highest in tournaments with the same number of winner and loser prizes. We can only conjecture that this behavioral pattern is induced by a misperception of participants regarding the marginal probability of winning. Therefore, we speculate that behavior may be explained by the achievement motivation theory proposed by ATKINSON (1958). However, this explanation does not seem to be well applicable to the participants' sabotage behavior. The exertion of the destructive activity seems to be driven by two additional motives: On the one hand, subjects more often refrain from exerting sabotage than from exerting effort which might be due to efficiency considerations. On the other hand, on average sabotage is inefficiently high which might result from inequity averse individuals who try to reduce the principal's output. Moreover, we find that the variation of activities from both activity dimensions is lowest in the treatments with the highest number of winner prizes per participant. This is in line with the finding that the number of nonparticipants exerting activities of zero is decreasing with an increasing fraction of winner prizes.

By testing our simple tournament model we can confirm that sabotage happens when easily feasible. Further research should provide insights into how sabotage behavior could be mitigated by adopting innovative tournament designs that do not allow the negative consequences of destructive activities to overrule the positive incentive effects of tournaments. 


\section{References}

ABBINK, Klaus and Abdolkarim SADRIEH (1995) RatImage - Research Assistance Toolbox for Computer-Aided Human Behavior Experiments. SFB Discussion Paper B-325, University of Bonn.

Anderhub, Vital, Simon GÄCHTER, and Manfred Königstein (2002) Efficient Contracting and Fair Sharing in a Principal-Agent Experiment, Experimental Economics, 5 (1), 5-25.

AtKInson, John W. (1958) Motives in Fantasy, Action, and Society, Princeton, NJ: Van Nostrand.

AtKInson, John W. (1984) An Introduction to Motivation, Princeton, NJ: Van Nostrand.

BECKER, Brian E. and Mark A. Huselid (1992) Incentive Effects of Tournament Compensation Systems. Administrative Science Quarterly 37, 336-350.

Boyle, Matthew (2001) Performance Reviews: Perilous Curves Ahead. Fortune, 15 May 2001.

Bull, Clive, Andrew Schotter, and Keith Weigelt (1987) Tournaments and Piece Rates: An Experimental Study. Journal of Political Economy 95, 1-33.

Cabrales, Antonio and Gary Charness (2000) Optimal Contracts, Adverse Selection and Social Preferences: An Experiment, Working Paper, UPF 478, Universitat Pompeu Fabra.

ChARnEsS, Gary and Mathew RABIN (2002) Understanding Social Preferences with Simple Tests, Quarterly Journal of Economics 117, 817-869.

CHEN, Kong-Pin (2003) Sabotage in Promotion Tournaments, Journal of Law, Economics and Organization, 19 (1), 199-139.

CoOKSON Richard (2000): Framing Effects in Public Goods Experiments, Experimental Economics 3, 55-79.

Drago, Robert W. and Gerald T. Garvey (1998) Incentives for Helping on the Job. Theory and Evidence. Journal of Labor Economics 16(1), 1-15.

EhrenBerG, Ronald G. and Michael L. Bognanno (1990) The Incentive Effects of Tournaments Revisited: Evidence from the European PGA Tour. Industrial and Labor Relations Review 43, 74-88.

ERIKSSON, Tor (1999) Executive Compensation and Tournament Theory: Empirical Tests on Danish Data. Journal of Labor Economics 17(2), 262-280.

FALK, Armin and Ernst FEHR (2003) Why Labour Market Experiments?, Labour Economics, 10, 399-406.

FEHR, Ernst and Klaus SchmidT (1999) A Theory of Fairness, Competition, and Cooperation, Quarterly Journal of Economics 114, 817-868.

FeHR, Ernst, Alexander KLeIN, and Klaus SchmidT (2001) Fairness, Incentives and Contractual Incompleteness, Discussion Paper, University of München.

Garicano, Luis and Ignacio Palacios-Huerta (2000) An Empirical Examination of Multidimensional Effort in Tournaments. Discussion Paper, University of Chicago.

GiBBOns, Robert (1998) Incentives in Organizations. Journal of Economic Perspectives 12, 115-132.

Grund, Christian (2005) The Wage Policy of Firms - Comparative Evidence for the U.S. and Germany from Personnel Data, The International Journal of Human Resource Management 15, 104-119.

GÜTH, Werner, Wolfgang KLOSE, Manfred KÖNIGSTEIN, and Joachim SCHWALBACH (1998) An Experimental Study of a Dynamic Principal-Agent Relationship, Managerial and Decision Economics, 19, 327-341.

GÜTH, Werner, Manfred KöNigstein, Judit KovÁcs, and Eniko ZALA-Mezo (2001) Fairness Within Firms: The Case of One Principal and Multiple Agents, Schmalenbach Business Review, 53(2), 82-101.

HARbring, Christine and Bernd IRLenbusch (2003a) An Experimental Study on Tournament Design. Labour Economics 10, 443-464.

HARBring, Christine and Bernd IRLEnBusch (2003b) Zur Interaktion von Arbeitgeber und Arbeitnehmern in Turnieren mit Sabotage, Zeitschrift für Betriebswirtschaft, Ergänzungsheft Personalmanagement, 19-41.

HARBRING, Christine and Bernd IRLENBuSCH (2004) Anreize zu produktiven und destruktiven Anstrengungen durch relative Entlohnung, Zeitschrift für betriebswirtschaftliche Forschung, September, 546-577.

HARBring, Christine and Gabriele K. Ruchala (2005) On the Competition of Asymmetric Agents, mimeo, University of Bonn and University of Erfurt. 
HaRbRING, Christine and Bernd IrLenbusch (2005) Incentives in Tournaments with Endogenous Prize Selection. Forthcoming: Journal of Institutional and Theoretical Economics.

Harbring, Christine, Bernd Irlenbusch, Matthias KräKel, and Reinhard Selten (2004) Sabotage in Asymmetric Contests, mimeo, University of Cologne and London School of Economics.

IRLENBUSCH, Bernd and Dirk SLIWKa (2005) Incentives, Decision Frames, and Motivation Crowding Out - An Experimental Investigation, mimeo, University of Cologne and London School of Economics.

KRÄKEL, Matthias (2000) Relative Deprivation in Rank-Order Tournaments. Labour Economics 7, 385-407.

LAZEAR, Edward P. (1989) Pay Equality and Industrial Politics. Journal of Political Economy 97, 561-80.

LAZEAR, Edward P. (1999) Personnel Economics: Past Lessons and Future Directions - Presidential Address to the Society of Labor Economists. Journal of Labor Economics 17(2), 199-236.

LAZEAR, Edward P. and Sherwin H. Rosen (1981) Rank-Order Tournaments as Optimum Labor Contracts. Journal of Political Economy 89, 841-64.

MaLColmson, James M. (1984) Work Incentives, Hierarchy, and Internal Labor Markets, Journal of Political Economy, 92, 486-507.

Malcolmson, James M. (1986) Rank-Order Contracts for a Principal with Many Agents, Review of Economic Studies, 53, 807-817.

MAin, Brian G.M., Charles A. O’ReILLY III, and James WADE (1993) Top Executive Pay: Tournament or Teamwork? Journal of Labor Economics 11(4), 606-28.

McLaughLin, Kenneth J. (1988) Aspects of Tournament Models, Research in Labor Economics, 9, 225-256.

Mood, Alexander M., Franklin A. Graybill, Duane C. BoEs (1974) Introduction the Theory of Statistics, $3^{\text {rd }}$ edition, Mc Graw-Hill.

MÜLLER, Wieland and Andrew SchotTer (2003) Workaholics and Drop Outs in Optimal Organizations, Discussion Paper, Tilburg University and New York University.

MuRPHY, Kevin (1992) Performance Measurement and Appraisal: Motivating Managers to Identify and Reward Performance. William Bruns (ed.): Performance Measurement, Evaluation, and Incentives. Harvard Business School 1992.

Nalbantian, Haig R. and Andrew SchotTer (1994) Productivity under Group Incentives: An Experimental Study. New York University Research Report \#94-04.

NAlBantian, Haig R. and Andrew SchOTTER (1997) Productivity under Group Incentives: An Experimental Study. American Economic Review 87, 314-41.

O’KeEfFE, Mary, W. Kip ViscusI, and Richard J. ZecKhauser (1984) Economic Contests: Comparing Reward Schemes, Journal of Labor Economics, 2, 27-56.

ORRISON, Alannah, Andrew SCHOTTER, and Keith WeIgelt (2004) Multiperson Tournamants: An Experimental Examination, Management Science, 50, 268-279.

PFEFFER, Jeffrey and Robert I. SuTtON (1999) The Knowing-Doing Gap: How Smart Companies Turn Knowledge into Action, Harvard Business School Press, Cambridge.

Prendergast, Canice (1999) The Provision of Incentives in Firms. Journal of Economic Literature 37, 7-63.

Schotter, Andrew and Keith Weigelt (1992) Asymmetric Tournaments, Equal Opportunity Laws, and Affirmative Action: Some Experimental Results. Quarterly Journal of Economics, 107, 511-539.

SCHOTTER, Andrew (1996) Worker Trust, System Vulnerability and Performance of Work Groups. New York University Research Report \#94-04.

VAN DiJK, Frans, Joep Sonnemans, Frans VAN Winden (2001) Incentive Systems in a Real Effort Experiment. European Economic Review 45, 187-214.

Weigelt, Keith, Janet DuKerich, and Andrew SchotTer (1989) Reactions to Discrimination in an Incentive Pay Compensation Scheme: A Game-Theoretic Approach. Organizational Behavior and Human Decision Processes 44, 26-44. 


\section{Appendix: Marginal Probabilities of Winning}

We show that given our assumptions in a symmetric equilibrium the marginal probabilities of winning depend only on the size of the interval from which the random component in the production function is drawn. In what follows we concentrate on the marginal probability regarding the chosen effort level. Let $\lambda n$ be the number of winner prizes $(0<\lambda<1)$, i.e., agents with the $(1-\lambda) n$th lowest output or less receive the loser prize. In a symmetric Nash equilibrium each competitor of agent $i$ will choose the same effort level $e^{*}$ and the same sabotage level $s^{*}$. Therefore, agent $i$ will receive the winner prize if her output is higher than the $(1-\lambda) n$th lowest output of the other $(n-1)$ workers, i.e., if $e_{i}+\varepsilon_{i}-(n-1) s^{*}>e^{*}-s_{i}-(n$ $-2) s^{*}+\hat{\varepsilon}$ with $\hat{\varepsilon}$ as the $(1-\lambda) n$th lowest of $(n-1)$ order statistics.

The probability for this event is $F\left(e_{i}, e_{-i}, s_{i}, s_{-i}\right)=\operatorname{Pr}\left\{X<e_{i}-e^{*}-(n-1) s^{*}+s_{i}+(n-\right.$ 2) $\left.s^{*}\right\}=F_{X}\left(e_{i}-e^{*+} s_{i}-s^{*}\right)$ with $X:=\hat{\varepsilon}-\varepsilon_{i}$ and $F_{X}(\cdot)$ as the distribution function of $X$. Agent $i$ maximizes her expected payoff $E \Pi_{i}\left(e_{i}\right)=m+\Delta F_{X}\left(e_{i}-e^{*}+s_{i}-s^{*}\right)-C_{e}\left(e_{i}\right)-C_{s}\left(s_{i}\right)$. From the assumption of a symmetric equilibrium $\left(e_{j}=e^{*}\right.$ and $s_{j}=s^{*}$ for $\left.j=1, \ldots, n\right)$ it follows that the equilibrium effort is characterized by $C_{e}{ }^{\prime}\left(e^{+}\right)=\Delta f_{X}(0)$ and $C_{s}{ }^{\prime}\left(s^{+}\right)=\Delta f_{X}(0)$ with $f_{X}(\cdot)=F_{X}{ }_{X}(\cdot)$ as $X^{\prime}$ 's density function. This leads to $e^{*}=C_{e}{ }^{,-1}\left(\Delta f_{X}(0)\right)$ as well as $s^{*}=C_{s}{ }^{,-1}\left(\Delta f_{X}(0)\right)$ with $C^{,-1}(\cdot)$ as the inverse function of the marginal cost function (note that $C_{e}{ }^{,-1}(\cdot)$ and $C_{s}{ }^{,-1}(\cdot)$ are linearly increasing). In order to obtain the equilibrium effort it remains to derive the explicit probability $f_{X}(0)$.

Let $F\left(\varepsilon_{j}\right)$ and $f\left(\varepsilon_{j}\right)$ be the distribution function and the density function of each of the $j=1, \ldots, n$ i.i.d. random components $\varepsilon_{j}$. The density function of the $(1-\lambda) n$th lowest of $(n-1)$ order statistics (see MoOD, GRAYBILL and BOES 1974) can be written as

$$
\begin{aligned}
f_{(1-\lambda) n ;(n-1)}(\hat{\varepsilon}) & =\frac{(n-1) !}{[(1-\lambda) n-1] ![\lambda n-1] !} F^{n-\lambda n-1}(\hat{\varepsilon})[1-F(\hat{\varepsilon})]^{\lambda n-1} f(\hat{\varepsilon}) \\
& =\frac{(n-1) !}{[(1-\lambda) n-1] ![\lambda n-1] !}\left[\frac{\bar{\varepsilon}+\hat{\varepsilon}}{2 \bar{\varepsilon}}\right]^{n-\lambda n-1}\left[1-\frac{\bar{\varepsilon}+\hat{\varepsilon}}{2 \bar{\varepsilon}}\right]^{\lambda n-1} \frac{1}{2 \bar{\varepsilon}} \\
& =\frac{(n-1) !}{[(1-\lambda) n-1] ![\lambda n-1] !} \frac{(\bar{\varepsilon}+\hat{\varepsilon})^{n-\lambda n-1}(\bar{\varepsilon}-\hat{\varepsilon})^{\lambda n-1}}{(2 \bar{\varepsilon})^{n-1}}
\end{aligned}
$$

Now let us consider the density function $f_{X}(x)$ for the random variable $X:=\hat{\varepsilon}-\varepsilon_{i}$. Because $\varepsilon_{i}$ and $\hat{\varepsilon}$ are stochastically independent, we have

$$
f_{X}(x)=\int_{X=\hat{\varepsilon}-\varepsilon_{i}} f(\varepsilon) f_{(1-\lambda) n ;(n-1)}(\varepsilon+x) d \varepsilon
$$




$$
=\frac{(n-1) !}{[(1-\lambda) n-1] ![\lambda n-1] !} \int_{X=\hat{\varepsilon}-\varepsilon_{i}} \frac{(\bar{\varepsilon}+\varepsilon+x)^{n-\lambda n-1}(\bar{\varepsilon}-\varepsilon-x)^{\lambda n-1}}{(2 \bar{\varepsilon})^{n}} d \varepsilon
$$

In order to compute the density function $f_{X}(x)$ we have to fill in the limits of the integral. We know that

$-\bar{\varepsilon} \leq \varepsilon \leq \bar{\varepsilon}$

$-\bar{\varepsilon} \leq \hat{\varepsilon} \leq \bar{\varepsilon} \Leftrightarrow-\bar{\varepsilon} \leq \varepsilon+x \leq \bar{\varepsilon} \Leftrightarrow-x-\bar{\varepsilon} \leq \varepsilon \leq \bar{\varepsilon}-x$.

The random variable $X:=\hat{\varepsilon}-\varepsilon_{i}$ is distributed over the interval $[-2 \bar{\varepsilon}, 2 \bar{\varepsilon}]$, which can be divided into two subintervals: (i) $[-2 \bar{\varepsilon}, 0]$ and (ii) $[0,2 \bar{\varepsilon}]$. For $x \leq 0$ we obtain from (i) together with $\left({ }^{*}\right)$ and $\left({ }^{* *}\right)$ that $-x-\bar{\varepsilon} \leq \varepsilon \leq \bar{\varepsilon}$. Accordingly, for $x>0$ we obtain from (ii) together with $\left({ }^{*}\right)$ and $\left({ }^{* *}\right)$ that $-\bar{\varepsilon} \leq \varepsilon \leq \bar{\varepsilon}-x$.

This gives us

$$
\frac{(n-1) !}{[(1-\lambda) n-1] ![\lambda n-1] !} \int_{-x-\bar{\varepsilon}}^{\bar{\varepsilon}} \frac{(\bar{\varepsilon}+\varepsilon+x)^{n-\lambda n-1}(\bar{\varepsilon}-\varepsilon-x)^{\lambda n-1}}{(2 \bar{\varepsilon})^{n}} d \varepsilon \quad \text { if }-2 \bar{\varepsilon} \leq x \leq 0
$$

$f_{X}(x)=$

$$
\frac{(n-1) !}{[(1-\lambda) n-1] ![\lambda n-1] !} \int_{-\bar{\varepsilon}}^{\bar{\varepsilon}-x} \frac{(\bar{\varepsilon}+\varepsilon+x)^{n-\lambda n-1}(\bar{\varepsilon}-\varepsilon-x)^{\lambda n-1}}{(2 \bar{\varepsilon})^{n}} d \varepsilon \quad \text { if } 0<x \leq 2 \bar{\varepsilon}
$$

In equilibrium it holds that $x=0$. It follows that

$$
f_{X}(0)=\frac{(n-1) !}{[(1-\lambda) n-1] ![\lambda n-1] !(2 \bar{\varepsilon})^{n}} \int_{-\bar{\varepsilon}}^{\bar{\varepsilon}}(\bar{\varepsilon}+\varepsilon)^{n-\lambda n-1}(\bar{\varepsilon}-\varepsilon)^{\lambda n-1} d \varepsilon
$$

Repeated partial integration gives

$$
\begin{aligned}
& \int_{-\bar{\varepsilon}}^{\bar{\varepsilon}}(\bar{\varepsilon}+\varepsilon)^{n-\lambda n-1}(\bar{\varepsilon}-\varepsilon)^{\lambda n-1} d \varepsilon= \\
& =\left[\frac{1}{n-\lambda n}(\bar{\varepsilon}-\varepsilon)^{\lambda n-1}(\bar{\varepsilon}+\varepsilon)^{n-\lambda n}+\frac{(\lambda n-1)}{(n-\lambda n)(n-\lambda n+1)}(\bar{\varepsilon}-\varepsilon)^{\lambda n-2}(\bar{\varepsilon}+\varepsilon)^{n-\lambda n+1}+\ldots+\right. \\
& =\left[\frac{(\lambda n-1) !}{(n-\lambda n)(n-\lambda n+1) \ldots(n-1)}(2 \bar{\varepsilon})^{n-1}\right]
\end{aligned}
$$

Thus, the density reduces to

$$
f_{X}(0)=\frac{1}{2 \bar{\varepsilon}}
$$




\section{Appendix: Instructions}

$\{$ Treatment $n=4, \lambda=1 / 4$, original instructions were in German; they are available from the authors upon request\}

\section{Rounds, Groups and Roles}

- You are participating in an experiment of $\mathbf{2 0}$ rounds.

- You will be assigned to a group of 5 participants. During the experiment you will only interact with participants of your group. The group is randomly assigned and is kept constant throughout the whole experiment. It is not announced which participants are assigned to one group. There are two red and two blue groups.

- Each participant has one of two roles: $\mathbf{1}$ participant is of type I and $\mathbf{4}$ participants are of type II.

- The participant of type I does not have to decide anything.

- The task of the participants of type II is to choose a number A and a number B in each round which determine the result.

\section{Payoffs}

- Costs and payoffs are given in the fictitious currency „Taler“.

Type II:

- The results of the participants of type II determine the amount of their payoffs. The participant with the highest result receives a high payment, and the three participants with the lowest results receive a low payment. (In case of identical results a fair random move decides who receives a high and who a low payment.)

- The high payment is $\mathbf{2 0 0}$ Talers, and low payment is $\mathbf{1 0 0}$ Talers.

- The cost for number $A$ and for number $B$, which the participant has chosen are subtracted from this payment. This results in the payoff of the round.

\section{Type I:}

- The participant of type I receives half of the results of the participants of type II in her/his group. In addition, she/he receives 200 Talers in each round.

\section{Procedure of a round and calculation of results}

- Each participant of type II chooses a number $\mathbf{A}$ from the set $\{0, \ldots, 100\}$ and a number $\mathbf{B}$ from the set $\{0, \ldots, 50\}$. For both numbers a participant has to bear the costs listed in the two cost tables. The higher the numbers chosen the higher are the costs.

- For each participant of type II a random number is drawn independently from the set $\{-60, \ldots,+60\}$. Each number is drawn with the same probability.

- The result of a participant is the sum of her/his random number and the number $A$ chosen by her/him. Moreover, all numbers B are deducted which the three other participants of type II have chosen. Thus, the result of a participant of type II increases with the own number $A$ and decreases with the numbers B of the other three participants of type II.

$$
\text { Result = own number } \mathrm{A} \text { - numbers } \mathrm{B} \text { of other participants }+ \text { random number }
$$

A participant of type II is only informed about her/his own payoff (not her/his result) and the payoff of the participant of type I. The participant of type I is informed about the results of the other four participants in each round.

At the end of the experiment the sum of all payoffs of each round is exchanged at an exchange rate of $0.51 €$ per 100 Talers. 